\title{
The Optimal Replenishment Policy under Trade Credit Financing with Ramp Type Demand and Demand Dependent Production Rate
}

\author{
Juanjuan Qin' and Weihua Liu' \\ ${ }^{1}$ Business School, Tianjin University of Finance and Economics, Tianjin 300222, China \\ ${ }^{2}$ College of Management and Economics, Tianjin University, Tianjin 300222, China \\ Correspondence should be addressed to Juanjuan Qin; tjufeqin@163.com
}

Received 28 February 2014; Accepted 12 May 2014; Published 19 June 2014

Academic Editor: Xiang Li

Copyright (c) 2014 J. Qin and W. Liu. This is an open access article distributed under the Creative Commons Attribution License, which permits unrestricted use, distribution, and reproduction in any medium, provided the original work is properly cited.

\begin{abstract}
This paper investigates the optimal replenishment policy for the retailer with the ramp type demand and demand dependent production rate involving the trade credit financing, which is not reported in the literatures. First, the two inventory models are developed under the above situation. Second, the algorithms are given to optimize the replenishment cycle time and the order quantity for the retailer. Finally, the numerical examples are carried out to illustrate the optimal solutions and the sensitivity analysis is performed. The results show that if the value of production rate is small, the retailer will lower the frequency of putting the orders to cut down the order cost; if the production rate is high, the demand dependent production rate has no effect on the optimal decisions. When the trade credit is less than the growth stage time, the retailer will shorten the replenishment cycle; when it is larger than the breakpoint of the demand, within the maturity stage of the products, the trade credit has no effect on the optimal order cycle and the optimal order quantity.
\end{abstract}

\section{Introduction}

Along with the globalization of the market and increasing competition, the enterprises always take trade credit financing policy to promote sales, increase the market share, and reduce the current inventory levels. As a result, the trade credit financing play an important role in business as a source of funds after Banks or other financial institutions. In the traditional inventory economic order quantity (EOQ) model, it is assumed that the retailer must pay for the products when receiving them. In practice the suppliers often provide the delayed payment time for the payment of the amount owed. Usually, there is no interest charged for the retailer if the outstanding amount is paid in the allowable delay. However, if the payment is unpaid in full by the end of the permissible delay period, interest is charged on the outstanding amount.

The optimal inventory policy is also influenced by the market demand and the production rate with the trade credit. For the market demand, it is always changing fast and influenced by many factors such as the price $[1,2]$, the inventory level $[3,4]$, and the stage of the product life time $[5,6]$. For the rapid development of the technology and the quickly changing consumer tastes, the products are likely to face the problem of short life cycle, which in return forces the suppliers to frequently promote new products for a competition purpose. A demand model about product introduction is widely used with the ramp type function of time, which assumes that the demand is a linear growth with respect to time (growth stage) and, up to a certain time, reaches a climax and eventually remains to be the peak sales (maturity stage). In addition to the new products introduction, holiday-related products, such as those for Christmas season, are experimentally shown to fit this type of demand rate. On the other hand, when the market demand is better, the supplier will provide a higher production rate; if the market demand is shrinking, the supplier will reduce the production rate. Therefore, the production rate is demand dependent production rate.

The optimal inventory policy is not only related to the market demand but also influenced by the production rate. 
As a result, in-depth research is required on the inventory replenishment decisions. Therefore, this study extends the EOQ models in the several ways as follows. First, trade credit financing is introduced to the traditional EOQ models. The retailer is offered by the supplier with a delayed payment time. Second, the ramp type demand is introduced to the EOQ models with the trade credit financing. The demand is nearly a constant in the maturity stage. During the growth time, the demand of the products is increasing with time. Furthermore, the production rate dependent on demand is introduced to the EOQ models with trade credit financing considering the ramp type demand for the first time.

\section{Literature Review}

2.1. Trade Credit. The trade credit is studied by many scholars from the aspects of finance, accounting, and operations management. Finance and accounting research mainly focused on the study of trade credit enterprise's cash flow, discussing the nature of the trade credit and its impact. In the area of operation management research, mainly from the angle of cash flow and logistics coordination, based on the traditional economic order quantity model framework, weigh the cost of capital cost elements such as fixed ordering cost, storage cost, and profit (or other elements), to analyze the supply chain inventory control and coordination problems. Our research is mainly felt in the operation management flow.

The inventory replenishment policies under trade credit financing have been studied intensively. Most papers discussed the EOQ or EPQ inventory models under trade credit financing all based on the assumptions that the demand rate is a constant and the infinite production rate. The EOQ model with the trade credit financing is put forward for the first time by Goyal [7], which is extended by Chu et al. [8] considering the deteriorated products. The models with the exponential deterioration rate of the items are discussed by Aggarwal and Jaggi [9]. The order strategies are studied by Jamal et al. [10] and Chang and Dye [11] allowing the shortage under delayed payment and deteriorating conditions. The unit selling price is not the same as the unit product costs in the model of Teng [12]. The economic production quantity model is researched by Chung and Huang [13] considering the manufacturer offering the retailer the delayed payment policy. Uthayakumar and Parvathi [14] analyze the supply chain of a single vendor and a single buyer for a single product, taking into consideration the effect of deterioration and credit period incentives with a constant demand and the infinite replenishment rate. In addition, some authors considered the two levels of the delayed payment. Huang [15] first extended Goyal's model to analyze the two levels of the trade credit policy, the manufacturer's credit period available to retailers as $M$, and the retailers provide the customers a credit period $N, M>N$. And then, Hao et al. [16], Huang [17], and Teng and Chang [18] extend the models of Huang [15]. Recently, Du et al. [19] investigate the coordination of two-echelon supply chains using wholesale price discount and credit option. Wu et al. [20] research the optimal credit period and lot size for deteriorating items with expiration dates under two-level trade credit financing.

2.2. Ramp Type Demand Rate. A number of papers in published literature have extensively studied inventory problem by assuming this ramp type demand rate. Under the assumption, Hwang and Shinn [21] proposed the optimal replenishment policy for perishable seasonal products in a season with ramp type time dependent demand. Panda et al. [22] discussed the inventory models with ramp type demand rate, partial backlogging, and Weibull deterioration rate. Skouri et al. [23] presented an economic production quantity models for deteriorating items with ramp type demand. Manna and Chaudhuri [24] introduced an EOQ inventory model for Weibull distributed deteriorating items under ramp type demand and shortages. Mandal [25] analyzed the supply chain model with stochastic lead time under imprecise partially backlogging and fuzzy ramp-type demand for expiring items. S. R. Singh and C. Singh [26] investigated the inventory model for ramp type demand, time dependent deteriorating items with salvage value, and shortages. Mishra and Singh [27] proposed two-warehouse inventory model with ramp-type demand and partially backlogged shortages. Agrawal and Banerjee [28] discussed a finite time horizon EOQ model with ramp type demand rate under inflation and time discounting with the infinite replenishment rate. Roy and Chaudhuri [29] studied the computational approach to an inventory model with ramp type demand and linear deterioration. Recently, Agrawal et al. [30] analyze a twowarehouse inventory model, with the demand rate being a general ramp type function of time and the shortages are partially backlogged at a constant rate. Ahmed et al. [31] focus on the inventory model with the ramp type demand rate, the partial backlogging, and general deterioration rate. Saha [32] discusses the optimal order quantity of the retailer with quadratic ramp type demand under supplier trade credit financing.

However, the problems of payment delay linked to the ramp type demand rate have not received much attention. The most related literatures to our study are as follows. Mishra and Singh [33] discussed the optimal order policy for single period products under payment delay with ramp type demand rate; Huang et al. [34] made some efforts to build an inventory system for deteriorating products, with ramp type demand rate, under two-level trade credit policy considering the shortages and the partially backlogged unsatisfied demand. But they do not consider the demand dependent production rate.

2.3. Demand Dependent Production Rate. For the trade credit, the researchers attempting to solve the problems mostly assume that the production rate is infinite or a constant value. However, the infinite or a constant replenishment rate of the inventory models is inconsistent with the actual industrial practices. When the market demand is better, the supplier will provide a higher production rate; if the market demand is shrinking, the supplier will reduce the production rate. In the traditional EOQ or EPQ models without the 
trade credit financing, Darzanou and Skouri [35] presented a production inventory system for deteriorating items with demand rate being a linearly ramp type function of time and production rate being proportional to the demand rate. The two models without shortages and with shortages were discussed. Both models were studied assuming that the time point at which the demand is stabilized occurs before the production stopping time. Manna and Chiang [36] extend this model by considering that (a) for the model with no shortages the demand rate is stabilized after the production stopping time and (b) for the model with shortages the demand rate is stabilized after the production stopping time or after the time when the inventory level reaches zero or after the production restarting time. Recently, Skouri et al. [37] developed a more general integrated supplier retailer inventory model with a demand rate which is sensitive to the retailing price and a demand dependent production rate with two-level of trade credit financing, which did not consider the ramp type demand rate.

Therefore, based on the literatures above, we find that none of the above models explore the optimal replenishment policies of the retailer under trade credit financing with the ramp type demand and demand dependent production rate.

Given the analysis above, this paper developed inventory models under trade credit financing with ramp type demand and demand dependent production rate. In this inventory system, they might attribute to intricate correlations among the period to maturity stage $\mu$, the period of delayed payment $M$, the production time $t_{1}$, and the planning time interval $T$. We assume that the break point of the demand function $\mu$ is less than $T$. Otherwise, the models in the situation of the ramp type demand are the same as the models with the linear increasing demand function Teng et al. [6], which is not the subjective of this research, and without doubt $t_{1}<T$ holds. Still, there exist eight possible subcases discussed in this paper. The remainder of this paper is organized as follows. The notations and assumptions are introduced in Section 3. The inventory levels for $\mu \leq t_{1}$ and $\mu \geq t_{1}$ are presented in Section 4. Model formulations are developed where we have two inventory models $M \leq \mu$ and $M \geq \mu$ including eight subcases in Section 5, for which the algorithms are provided to obtain the optimal decisions. The numerical examples and sensitivity analysis then are conducted in Section 6 in association with managerial insights. Finally, Section 7 closes the paper with a conclusion.

\section{Notations and Assumptions}

To build the mathematical models, the following notations and assumptions are adopted in this paper.

\subsection{Notations}

\section{A: Ordering cost per order}

$t_{1}$ : The time at which the inventory level is at maximum for the situation $\mu \leq t_{1}$;

$\bar{t}_{1}$ : The time at which the inventory level is at maximum for the situation $t_{1} \leq \mu$
$S:$ The maximum inventory level at each scheduling period (cycle)

$c_{h}$ : The inventory holding cost per unit per unit time (excluding interest charges)

$c_{p}$ : The purchasing cost per unit

$s$ : The unit sale price

$k$ : The production rate with $k=r f(t)$

$R$ : The market demand with $R=f(t)$

$\mu$ : The break point of the demand function

$D_{0}$ : The rate of demand with the time during the demand increasing stage

$I_{i}(t)(i=1,2,3):$ The inventory level at time $t \in[0, T]$

$I_{e}$ : The interest rate earned per unit per unit of time

$I_{c}$ : The interest rate charged per unit per unit of time

$M$ : The offered credit period by the supplier

$T$ : The replenishment cycle time

TRC (T): The annual total relevant cost.

3.2. Assumptions. The following assumptions are used throughout in this paper.

(1) There is a single supplier and single retailer and they deal with a single product.

(2) The lead time is zero. The planning horizon is infinite. The shortage is not allowed.

(3) The initial and final inventory levels are both zero.

(4) The market demand for the item is assumed to be a ramp type function of time. At the first stage, the demand is increasing with the time, such as the introduction stage of the new products; but as the time increases, the demand will keep a constant, such as the maturity stage of the new product. That is, $R=$ $f(t)=D_{0}[t-(t-\mu) H(t-\mu)]$ at any time $t \geq 0$, where $D_{0}$ and $\mu$ are positive constants and $H(t-\mu)$ is the Heaviside's function defined as follows:

$$
H(t-\mu)= \begin{cases}1, & \text { if } t \geq \mu \\ 0, & \text { if } t<\mu .\end{cases}
$$

(5) For the production rate, when the market demand is high, the production will be improved; but when the market demand is low, the production rate will be down. Therefore, the production rate is related to the demand closely. In this paper, the production rate is assumed $k=r f(t)$ [38], where $r(>1)$ is a constant. In the production period, when the products have been produced, they will be delivered to the retailer instantaneously. That is, the replenishment rate of the retailer is $k$.

(6) The retailer would settle the account at $t=M$ and pay for the interest charges on items in stock at the rate $I_{c}$ over the interval $[M, T]$ as $T \geq M$. Alternatively, the retailer settles the account at $t=M$ and is not 


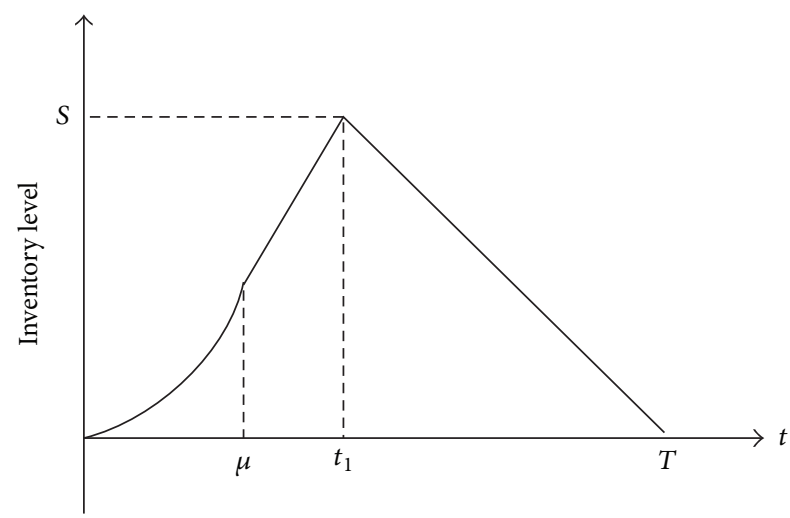

FIGURE 1: The inventory model for $\mu \leq t_{1}$.

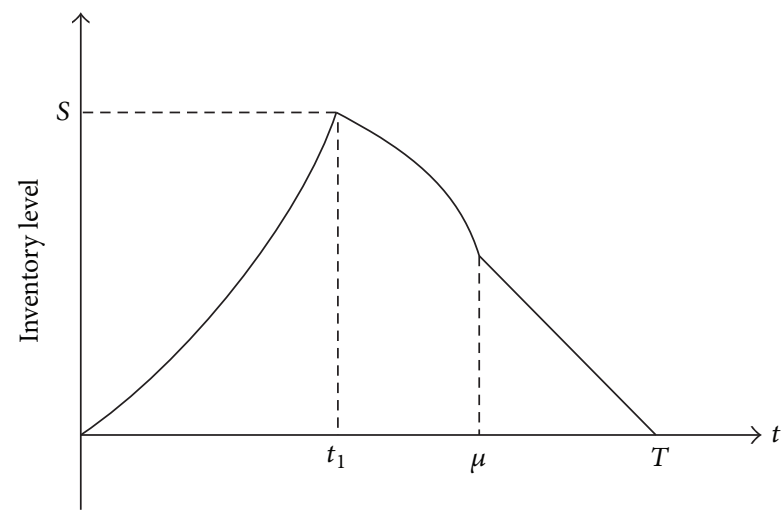

FIgURE 2: The inventory model for $t_{1} \leq \mu$.

required to pay any interest charges for items for the stock during the whole cycle as $T \leq M$. Before the settlement of the account, the retailer can use sales revenue to earn the interest up to the end of the period $M$ at the rate $I_{e}$.

(7) The break point of the demand function $\mu$ is less than $T$.

(8) For the inventory system, we analyze it in the Section 3 for two situations: $\mu \leq t_{1}$ and $t_{1} \leq \mu$.

Given the above, it is possible to build the mathematical inventory EOQ model with the trade credit financing.

\section{The Inventory Level}

4.1. Inventory Level for $\mu \leq t_{1}$. Based on the above notations and assumptions, the inventory system can be considered in the following. At the beginning, the stock level is zero. The production starts with zero stock level at time $t=0$, and the production stops at time $t=t_{1}$. Then the inventory level gradually diminishes due to demand, till it becomes zero at $t=T$. The whole process is repeated and the behaviour of the inventory system is described in Figure 1. Based on the Figure 1, we can know that the inventory cycle here has the three stages.
Hence, the variation of the inventory level $I(t)$ with respect to the time can be described by the following differential equations.

During the growth stage in the interval $[0, \mu]$, the demand rate is $D_{0} t$ and the replenishment rate is $r D_{0} t$. Therefore, the inventory level at time $t$ is governed by

$$
\frac{d I_{1}(t)}{d t}=(r-1) D_{0} t, \quad 0 \leq t \leq \mu,
$$

with the boundary conditions $I_{1}(0)=0$.

Similarly, during the maturity stage $\left[\mu, t_{1}\right]$, the demand rate is $D_{0} \mu$ and the replenishment rate is $r D_{0} \mu$. Therefore, the inventory level at time $t$ is governed by

$$
\frac{d I_{2}(t)}{d t}=(r-1) D_{0} \mu, \quad \mu \leq t \leq t_{1},
$$

with the boundary conditions $I_{2}\left(t_{1}\right)=S$.

Finally, at the maturity stage $\left[t_{1}, T\right]$, the demand rate is $D_{0} \mu$ and the production stops. Therefore, the inventory level at time $t$ is governed by

$$
\frac{d I_{3}(t)}{d t}=-D_{0} \mu, \quad t_{1} \leq t \leq T,
$$

with the boundary conditions $I_{3}\left(t_{1}\right)=S$ and $I_{3}(T)=0$.

Solving (2)-(4), the values of $I_{i}(t)(i=1,2,3)$ are as follows:

$$
\begin{aligned}
& I_{1}(t)=(r-1) \frac{1}{2} D_{0} t^{2}, \quad 0 \leq t \leq \mu, \\
& I_{2}(t)=(r-1) D_{0} \mu t-(r-1) \frac{1}{2} D_{0} \mu^{2}, \quad \mu \leq t \leq t_{1}, \\
& I_{3}(t)=D_{0} \mu(T-t), \quad t_{1} \leq t \leq T .
\end{aligned}
$$

In addition, using the boundary condition $I_{2}\left(t_{1}\right)=$ $I_{3}\left(t_{1}\right)=S$, we obtain

$$
(r-1) D_{0} \mu t_{1}-(r-1) \frac{1}{2} D_{0} \mu^{2}=D_{0} \mu\left(T-t_{1}\right) .
$$

Solving (6), we can obtain

$$
t_{1}=\frac{T+(1 / 2)(r-1) \mu}{r} .
$$

4.2. Inventory Level for $t_{1} \leq \mu$. The inventory system for $t_{1} \leq \mu$ considered in the following is the same as that in the situations of $t_{1} \geq \mu$. The behaviour of the inventory system is described in Figure 2. Based on the Figure 2, we can know that the inventory cycle here still has the three stages. The variation of the inventory level $I(t)$ with respect to the time can be described by the following differential equations.

During the growth stage in the interval $\left[0, t_{1}\right]$, the demand rate is $D_{0} t$ and the replenishment rate is $r D_{0} t$. Therefore, the inventory level at time $t$ is governed by

$$
\frac{d I_{1}(t)}{d t}=(r-1) D_{0} t, \quad 0 \leq t \leq t_{1},
$$

with the boundary conditions $I_{1}(0)=0$ and $I_{1}\left(t_{1}\right)=S$. 
Similarly, during the maturity stage $\left[t_{1}, \mu\right]$, the demand rate is $D_{0} t$ and the replenishment rate is zero. Therefore, the inventory level at time $t$ is governed by

$$
\frac{d I_{2}(t)}{d t}=-D_{0} t, \quad t_{1} \leq t \leq \mu,
$$

with the boundary conditions $I_{2}\left(t_{1}\right)=S$.

Finally, at the maturity stage $[\mu, T]$, the demand rate is $D_{0} \mu$ and there is no production. Therefore, the inventory level at time $t$ is governed by

$$
\frac{d I_{3}(t)}{d t}=-D_{0} \mu, \quad \mu \leq t \leq T,
$$

with the boundary conditions $I_{3}(T)=0$.

Solving (2)-(4), the values of $I_{i}(t)(i=1,2,3)$ are as follows:

$$
\begin{aligned}
& I_{1}(t)=(r-1) \frac{1}{2} D_{0} t^{2}, \quad 0 \leq t \leq t_{1}, \\
& I_{2}(t)=-\frac{1}{2} D_{0} t^{2}+\frac{1}{2} D_{0} \mu^{2}+D_{0} \mu(T-\mu), \quad t_{1} \leq t \leq \mu, \\
& I_{3}(t)=D_{0} \mu(T-t), \quad \mu \leq t \leq T .
\end{aligned}
$$

In addition, using the boundary condition $I_{1}\left(t_{1}\right)=$ $I_{2}\left(t_{1}\right)=S$, we obtain

$$
(r-1) \frac{1}{2} D_{0} t_{1}^{2}=-\frac{1}{2} D_{0} t_{1}^{2}+\frac{1}{2} D_{0} \mu^{2}+D_{0} \mu(T-\mu) .
$$

Solving (12), we can obtain

$$
\bar{t}_{1}=\sqrt{\frac{-\mu^{2}+2 \mu T}{r}} .
$$

\section{Mathematical Models and Solutions}

The annual total relevant cost consists of the following elements: ordering cost, holding cost, interest payable, and interest earned. The components are evaluated as in the following.

(1) Annual ordering cost: $A / T$.

(2) Annual stock holding cost (excluding the interest charges).

For $\mu \leq t_{1}$, the annual stock holding cost is

$$
\begin{aligned}
\frac{c_{h}}{T}\left[\int_{0}^{\mu} I_{1}(t) d t+\int_{\mu}^{t_{1}} I_{2}(t) d t+\int_{t_{1}}^{T} I_{3}(t) d t\right] \\
=\frac{c_{h}}{T}\left[(r-1) \frac{1}{6} D_{0} \mu^{3}+\frac{1}{2} r D_{0} \mu t_{1}^{2}\right. \\
\left.\quad-(r-1) \frac{1}{2} D_{0} \mu^{2} t_{1}+\frac{1}{2} D_{0} \mu T^{2}-D_{0} \mu t_{1} T\right] .
\end{aligned}
$$

For $t_{1} \leq \mu$, the annual stock holding cost is

$$
\begin{aligned}
\frac{c_{h}}{T}\left[\int_{0}^{\bar{t}_{1}} I_{1}(t) d t\right. & \left.+\int_{\bar{t}_{1}}^{\mu} I_{2}(t) d t+\int_{\mu}^{T} I_{3}(t) d t\right] \\
= & \frac{c_{h}}{T}\left[\frac{1}{6} r D_{0} \bar{t}_{1}^{3}-\frac{1}{6} D_{0} \mu^{3}\right. \\
& \left.\quad+\frac{1}{2} D_{0} \mu^{2} \bar{t}_{1}-D_{0} \mu T \bar{t}_{1}+\frac{1}{2} D_{0} \mu T^{2}\right] .
\end{aligned}
$$

(3) There are eight cases to occur in interest earned and interest charged for the items kept in stock per year.

From the value of $M$, we have two possible situations: $M \leq \mu$ and $M \geq \mu$. The different mathematical formulations are discussed in the following according to the two possible situations including eight cases.

\subsection{Model 1: The Inventory Models for the Case $M \leq \mu$}

\subsubsection{Case 1}

Case 1.1 ( $t_{1} \leq M \leq \mu \leq T$, shown in Figure 3). The annual interest charged will be paid for the inventory not being sold after the due date $M$. During the time $[M, \mu]$, the inventory level is $I_{2}(t)$; for the time $[\mu, T]$, the inventory level is $I_{3}(t)$. Therefore, the annual interest charged for the inventory not being sold after the due date $M$ is given by

$$
\begin{aligned}
\frac{c_{p} I_{c}}{T}\left[\int_{M}^{\mu} I_{2}(t) d t+\int_{\mu}^{T} I_{3}(t) d t\right] & \\
=\frac{c_{p} I_{c}}{T}[ & -\frac{1}{6} D_{0} \mu^{3}+\frac{1}{6} D_{0} M^{3} \\
& \left.\quad+\frac{1}{2} D_{0} \mu^{2} M-D_{0} \mu T M+\frac{1}{2} D_{0} \mu T^{2}\right] .
\end{aligned}
$$

During the time $[0, M]$, the retailer can use the sales to accumulate the interest. Therefore, the annual interest earned during the trade credit period is shown in the following:

$$
\frac{s I_{e}}{T}\left[\int_{0}^{M}(M-t) D_{0} t d t\right]=\frac{s I_{e}}{6 T} D_{0} M^{3} .
$$

Case $1.2\left(M \leq t_{1} \leq \mu \leq T\right.$, shown in Figure 4$)$. The annual interest charged will be paid for the inventory not being sold after the due date $M$. During the time $\left[M, \bar{t}_{1}\right]$, the inventory level is $I_{1}(t)$; for the time $\left[\bar{t}_{1}, \mu\right]$, the inventory level is $I_{2}(t)$; for the time $[\mu, T]$, the inventory level is $I_{3}(t)$. Therefore, the annual interest charged for the inventory not being sold after the due date $M$ is given by

$$
\begin{aligned}
\frac{c_{p} I_{c}}{T}\left[\int_{M}^{\bar{t}_{1}} I_{1}(t) d t+\int_{\bar{t}_{1}}^{\mu} I_{2}(t) d t+\int_{\mu}^{T} I_{3}(t) d t\right] & =\frac{c_{p} I_{c}}{T}\left[\frac{1}{6} r D_{0} \bar{t}_{1}^{3}-\frac{1}{6} D_{0} \mu^{3}+\frac{1}{2} D_{0} \mu^{2} \bar{t}_{1}\right. \\
& \left.\quad-D_{0} \mu T \bar{t}_{1}+\frac{1}{2} D_{0} \mu T^{2}-(r-1) \frac{1}{6} D_{0} M^{3}\right] .
\end{aligned}
$$




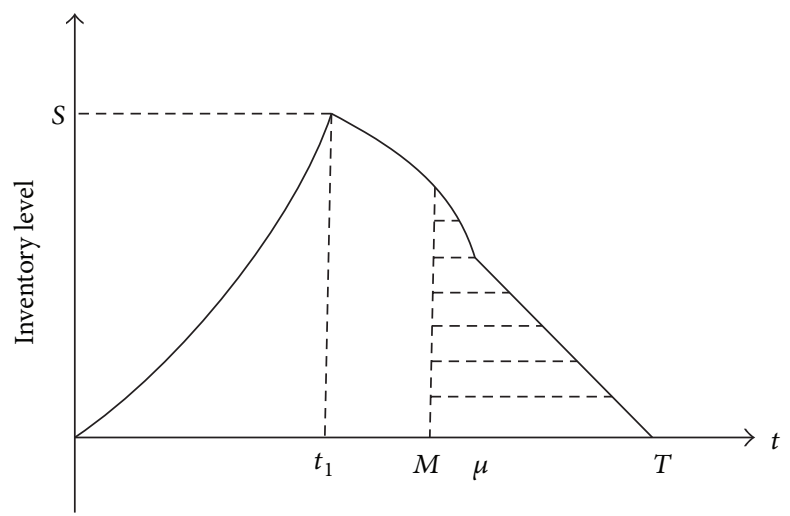

(a) Interest charged for $t_{1} \leq M \leq \mu \leq T$

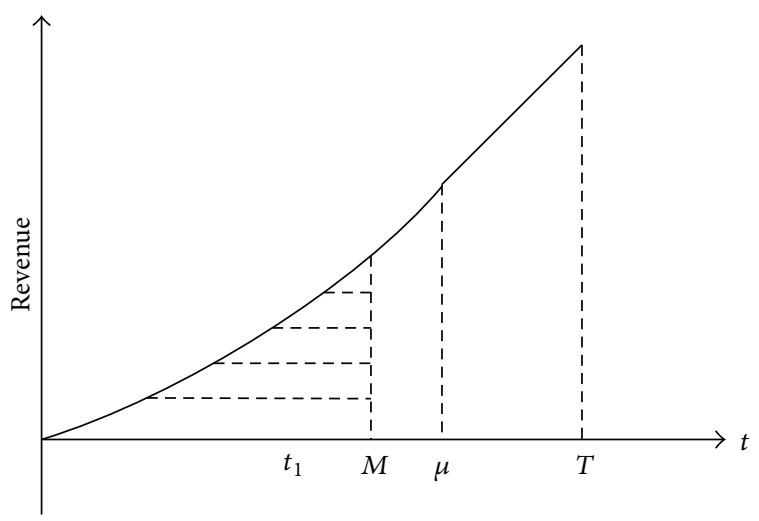

(b) Interest earned for $t_{1} \leq M \leq \mu \leq T$

FIGURE 3: Interest charged and interest earned for $t_{1} \leq M \leq \mu \leq T$.

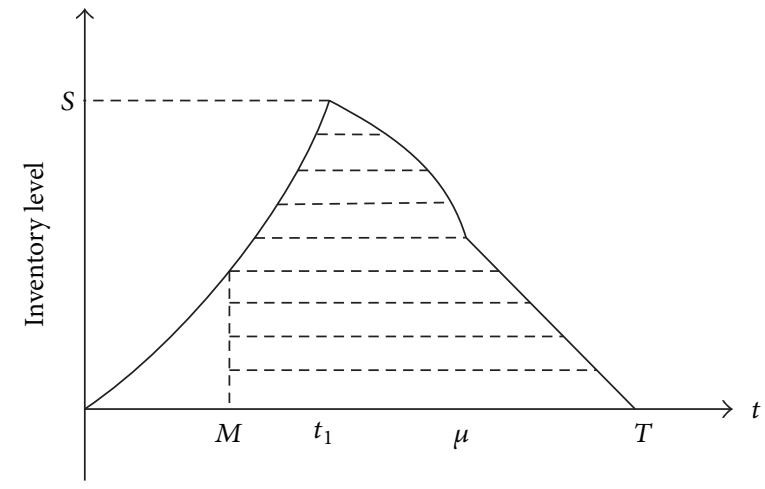

(a) Interest charged for $M \leq t_{1} \leq \mu \leq T$

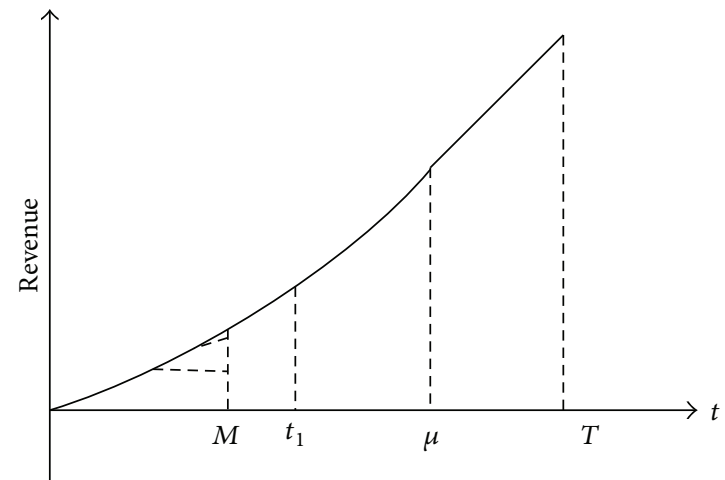

(b) Interest earned for $M \leq t_{1} \leq \mu \leq T$

FIGURE 4: Interest charged and interest earned for $M \leq t_{1} \leq \mu \leq T$.

During the time $[0, M]$, the retailer can use the sales to accumulate the interest. The annual interest earned during the trade credit period is presented in the following:

$$
\frac{s I_{e}}{T}\left[\int_{0}^{M}(M-t) D_{0} t d t\right]=\frac{s I_{e}}{6 T} D_{0} M^{3}
$$

Case 1.3 ( $M \leq \mu \leq t_{1} \leq T$, shown in Figure 5$)$. The annual interest charged will be paid for the inventory not being sold after the due date $M$. During the time $[M, \mu]$, the inventory level is $I_{1}(t)$; for the time $\left[\mu, t_{1}\right]$, the inventory level is $I_{2}(t)$; for the time $\left[t_{1}, T\right]$, the inventory level is $I_{3}(t)$. The annual interest charged for the inventory not being sold after the due date $M$ is shown by

$$
\begin{aligned}
& \frac{c_{p} I_{c}}{T}\left[\int_{M}^{\mu} I_{1}(t) d t+\int_{\mu}^{t_{1}} I_{2}(t) d t+\int_{t_{1}}^{T} I_{3}(t) d t\right] \\
& =\frac{c_{p} I_{c}}{T}\left[(r-1) \frac{1}{6} D_{0} \mu^{3}+\frac{1}{2} D_{0} \mu^{2} t_{1}\right. \\
& \left.\quad+\frac{1}{2} D_{0} \mu T^{2}-D_{0} \mu t_{1} T-\frac{1}{6}(r-1) D_{0} M^{3}\right] .
\end{aligned}
$$

For the interval $[0, M]$, the retailer can use the sales to accumulate the interest. The annual interest earned during the trade credit period is presented in the following:

$$
\frac{s I_{e}}{T}\left[\int_{0}^{M}(M-t) D_{0} t d t\right]=\frac{s I_{e}}{6 T} D_{0} M^{3} .
$$

5.2. The Optimal Replenishment Policy for the Model 1. The results in previous Section 4.1 lead to the following total cost functions.

(1) If $\mu \leq\left(M^{2} r+\mu^{2}\right) / 2 \mu$, that is, $\mu / \sqrt{r} \leq M \leq \mu$

$\operatorname{TRC}_{1}(T)$

$$
= \begin{cases}\operatorname{TRC}_{11}, & t_{1} \leq M \leq \mu \leq T, \text { that is } \mu \leq T \leq \frac{M^{2} r+\mu^{2}}{2 \mu} \\ \operatorname{TRC}_{12}, & M \leq t_{1} \leq \mu \leq T, \\ & \text { that is } \frac{M^{2} r+\mu^{2}}{2 \mu} \leq T \leq \frac{1}{2}(r+1) \mu \\ \operatorname{TRC}_{13}, & M \leq \mu \leq t_{1} \leq T, \text { that is } \frac{1}{2}(r+1) \mu \leq T .\end{cases}
$$




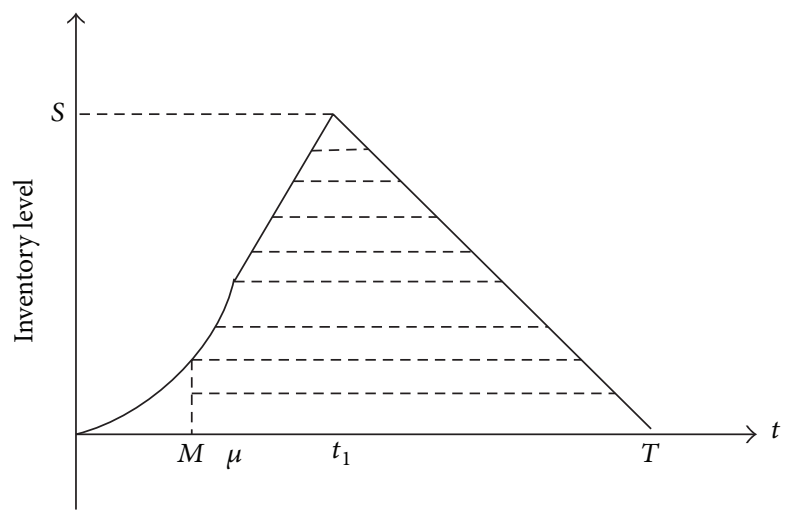

(a) Interest charged for $M \leq \mu \leq t_{1} \leq T$

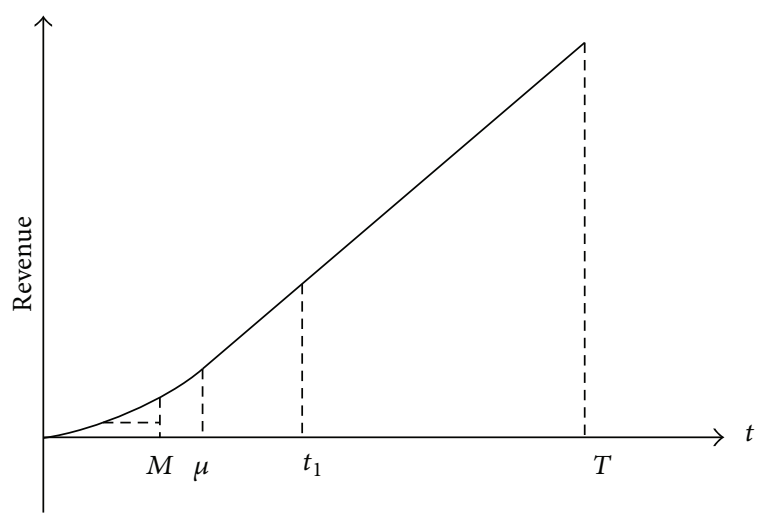

(b) Interest earned for $M \leq \mu \leq t_{1} \leq T$

FIGURE 5: Interest charged and interest earned for $M \leq \mu \leq t_{1} \leq T$.

(2) If $\mu \geq\left(M^{2} r+\mu^{2}\right) / 2 \mu$, that is $0 \leq M \leq \mu / \sqrt{r}$

$\operatorname{TRC}_{1}(T)$

$$
= \begin{cases}T R C_{12}, & M \leq t_{1} \leq \mu \leq T, \text { that is } \mu \leq T \leq \frac{1}{2}(r+1) \mu \\ T R C_{13}, & M \leq \mu \leq t_{1} \leq T, \text { that is } \frac{1}{2}(r+1) \mu \leq T,\end{cases}
$$

where

$T R C_{11}$

$$
\begin{aligned}
=\frac{A}{T}+\frac{c_{h}}{T}\left(\frac{1}{6} r D_{0} \bar{t}_{1}^{3}-\frac{1}{6} D_{0} \mu^{3}+\frac{1}{2} D_{0} \mu^{2} \bar{t}_{1}\right. & \left.-D_{0} \mu T \bar{t}_{1}+\frac{1}{2} D_{0} \mu T^{2}\right) \\
+\frac{c_{p} I_{c}}{T}( & -\frac{1}{6} D_{0} \mu^{3}+\frac{1}{6} D_{0} M^{3}+\frac{1}{2} D_{0} \mu^{2} M \\
& \left.-D_{0} \mu T M+\frac{1}{2} D_{0} \mu T^{2}\right)-\frac{s I_{e}}{6 T} D_{0} M^{3} ;
\end{aligned}
$$

$T R C_{12}$

$$
\begin{aligned}
=\frac{A}{T}+\frac{c_{h}}{T}( & \frac{1}{6} r D_{0} \bar{t}_{1}^{3}-\frac{1}{6} D_{0} \mu^{3}+\frac{1}{2} D_{0} \mu^{2} \bar{t}_{1} \\
& \left.\quad-D_{0} \mu T \bar{t}_{1}+\frac{1}{2} D_{0} \mu T^{2}\right) \\
+\frac{c_{p} I_{c}}{T}[ & \frac{1}{6} r D_{0} \bar{t}_{1}^{3}-\frac{1}{6} D_{0} \mu^{3}+\frac{1}{2} D_{0} \mu^{2} \bar{t}_{1}-D_{0} \mu T \bar{t}_{1} \\
& \left.+\frac{1}{2} D_{0} \mu T^{2}-(r-1) \frac{1}{6} D_{0} M^{3}\right]-\frac{s I_{e}}{6 T} D_{0} M^{3} ;
\end{aligned}
$$

$\operatorname{TRC}_{13}$

$$
\begin{aligned}
=\frac{A}{T}+\frac{c_{h}}{T}[ & (r-1) \frac{1}{6} D_{0} \mu^{3}+\frac{1}{2} D_{0} \mu^{2} t_{1} \\
& \left.+\frac{1}{2} D_{0} \mu T^{2}-D_{0} \mu t_{1} T\right]
\end{aligned}
$$

$$
\begin{aligned}
+\frac{c_{p} I_{c}}{T}[ & (r-1) \frac{1}{6} D_{0} \mu^{3}+\frac{1}{2} D_{0} \mu^{2} t_{1}+\frac{1}{2} D_{0} \mu T^{2} \\
& \left.-D_{0} \mu t_{1} T-\frac{1}{6}(r-1) D_{0} M^{3}\right]-\frac{s I_{e}}{6 T} D_{0} M^{3}
\end{aligned}
$$

The problem is $\min _{T} T R C_{1}(T)$. In order to obtain the optimal solutions, we should study each of the branches and then combine the results.

Theorem 1. (1) If $\alpha<0, T R C_{13}(T)$ is a convex function of $T$ for $T=(0, \infty)$. The optimal value of $T_{13}$ corresponds to $\min \left\{\operatorname{TRC}_{13}\left(\widetilde{T}_{13}\right), T R C_{13}((1 / 2)(r+1) \mu)\right\}$.

(2) If $\alpha \geq 0, T R C_{13}(T)$ is an increasing function with $T$ for $T=(0, \infty)$.

For $T \in[(1 / 2)(r+1) \mu, \infty)$, the optimal value $T_{13}$ is obtained when $T_{13}=(1 / 2)(r+1) \mu$.

It is similar to analyze the optimal solutions for other branches as Theorem 1. Therefore, we can obtain the solution procedure for determining the optimal replenishment cycle and the order quantity of the model 1 in the following algorithm.

\section{Algorithm 1.}

Step 1. Input the values for all parameters with $M \leq \mu$.

Step 2. Compare $\mu / \sqrt{r}$ and $M$. If $\mu / \sqrt{r} \leq M$, go to Algorithm 1.1; if $\mu / \sqrt{r} \geq M$, then go to Algorithm 1.2.

\section{Algorithm 1.1}

Step 1. Find the global minimum of $T R C_{11}(T)$, says $T_{11}$, as follows.

Step 1.1. Compute $\widetilde{T}_{11}$, if $\mu \leq \widetilde{T}_{11} \leq\left(M^{2} r+\mu^{2}\right) / 2 \mu$ and $f_{11}^{\prime \prime}\left(\widetilde{T}_{11}\right)$ $>0$, find the $\min \left\{T R C_{11}\left(\widetilde{T}_{11}\right), T R C_{11}(\mu), T R C_{11}\left(\left(M^{2} r+\right.\right.\right.$ 
$\left.\left.\left.\mu^{2}\right) / 2 \mu\right)\right\}$. And accordingly set $T_{11}$. Compute $Q_{11}$ and $T R C_{11}\left(T_{11}\right)$. Else, go to Step 1.2.

Step 1.2. Find the $\min \left\{T R C_{11}(\mu), T R C_{11}\left(\left(M^{2} r+\mu^{2}\right) / 2 \mu\right)\right\}$ and accordingly set $T_{11}$. Compute $Q_{11}$ and $T R C_{11}\left(T_{11}\right)$.

Step 2. Find the global minimum of $T R C_{12}(T)$, says $T_{12}$, as follows.

Step 2.1. Compute $\widetilde{T}_{12}$, if $\left(M^{2} r+\mu^{2}\right) / 2 \mu \leq \widetilde{T}_{12} \leq(r+1) \mu / 2$ and $f_{12}^{\prime \prime}\left(\widetilde{T}_{12}\right)>0$, find the $\min \left\{T R C_{12}\left(\widetilde{T}_{12}\right), T R C_{12}((r+\right.$ 1) $\left.\mu / 2), T R C_{12}\left(\left(M^{2} r+\mu^{2}\right) / 2 \mu\right)\right\}$ and accordingly set $T_{12}$. Compute $Q_{12}$ and $T R C_{12}\left(T_{12}\right)$. Else, go to Step 2.2.

Step 2.2. Find the $\min \left\{T R C_{12}((r+1) \mu / 2), T R C_{12}\left(\left(M^{2} r+\right.\right.\right.$ $\left.\left.\left.\mu^{2}\right) / 2 \mu\right)\right\}$ and accordingly set $T_{12}$. Compute $Q_{12}$ and $T R C_{12}\left(T_{12}\right)$.

Step 3. Find the global minimum of $T R C_{13}(T)$, says $T_{13}$, as follows.

Step 3.1. Compute $\widetilde{T}_{13}$, if $(r+1) \mu / 2 \leq \widetilde{T}_{13}$, and then set $T_{13}^{*}=$ $T_{13}$. Compute $Q_{13}$ and $T R C_{13}\left(T_{13}\right)$. Else, go to Step 3.2.

Step 3.2. Set $T_{13}=(r+1) \mu / 2$. Compute $Q_{13}$ and $T R C_{13}\left(T_{13}\right)$.

Step 4. Find the $\min \left\{T R C_{11}\left(T_{11}\right), T R C_{12}\left(T_{12}\right), T R C_{13}\left(T_{13}\right)\right\}$ and accordingly select the optimal value for $T_{1}$. Stop.

\section{Algorithm 1.2}

Step 1. Find the global minimum of $T R C_{12}(T)$, says $T_{12}$, as follows.

Step 1.1. Compute $\widetilde{T}_{12}$, if $\mu \leq \widetilde{T}_{12} \leq(r+1) \mu / 2$ and $f_{12}^{\prime \prime}\left(\widetilde{T}_{12}\right)>0$, find the $\min \left\{T R C_{12}\left(\widetilde{T}_{12}\right), T R C_{12}((r+1) \mu / 2), T R C_{12}(\mu)\right\}$ and accordingly set $T_{12}$. Compute $Q_{12}$ and $T R C_{12}\left(T_{12}\right)$. Else, go to Step 2.2.

Step 1.2. Find the $\min \left\{T R C_{12}((r+1) \mu / 2), T R C_{12}(\mu)\right\}$ and accordingly set $T_{12}$. Compute $Q_{12}$ and $T R C_{12}\left(T_{12}\right)$.

Step 2. Find the global minimum of $T R C_{13}(T)$, says $T_{13}$, as follows.

Step 2.1. Compute $\widetilde{T}_{13}$, if $(r+1) \mu / 2 \leq \widetilde{T}_{13}$, and then set $T_{13}=$ $\widetilde{T}_{13}$. Compute $Q_{13}$ and $T R C_{13}\left(T_{13}\right)$. Else, go to Step 2.2.

Step 2.2. Set $T_{13}=(r+1) \mu / 2$. Compute $Q_{13}$ and $T R C_{13}\left(T_{13}\right)$.

Step 3. Find the $\min \left\{T R C_{12}\left(T_{12}\right), T R C_{13}\left(T_{13}\right)\right\}$ and accordingly select the optimal value for $T_{1}$. Stop.

\subsection{Model 2: The Inventory Models for the Case $\mu \leq M$}

\subsubsection{Case $2(\mu \leq M \leq T)$}

Case $2.1\left(t_{1} \leq \mu \leq M \leq T\right)$. Similar to Case 1, the annual interest charged for the inventory not being sold after the due date $M$ is given by

$\frac{c_{p} I_{c}}{T} \int_{M}^{T} I_{3}(t) d t=\frac{c_{p} I_{c}}{T}\left(\frac{1}{2} D_{0} \mu T^{2}-D_{0} \mu T M+\frac{1}{2} D_{0} \mu M^{2}\right)$.
The annual interest earned during the trade credit period is shown in the following:

$$
\begin{array}{r}
\frac{s I_{e}}{T}\left[\int_{0}^{\mu}(M-t) D_{0} t d t+\int_{\mu}^{M}(M-t) D_{0} \mu d t\right] \\
\quad=\frac{s I_{e}}{T}\left(-\frac{1}{2} M D_{0} \mu^{2}+\frac{1}{6} D_{0} \mu^{3}+\frac{1}{2} D_{0} \mu M^{2}\right) .
\end{array}
$$

Case $2.2\left(\mu \leq t_{1} \leq M \leq T\right)$. The annual interest charged for the inventory not being sold after the due date $M$ is given by

$$
\begin{aligned}
\frac{c_{p} I_{c}}{T} & {\left[\int_{M}^{T} I_{3}(t) d t\right] } \\
& =\frac{c_{p} I_{c}}{T}\left(\frac{1}{2} D_{0} \mu T^{2}-D_{0} \mu T M+\frac{1}{2} D_{0} \mu M^{2}\right) .
\end{aligned}
$$

The annual interest earned during the trade credit period is shown in the following:

$$
\begin{array}{r}
\frac{s I_{e}}{T}\left[\int_{0}^{\mu}(M-t) D_{0} t d t+\int_{\mu}^{M}(M-t) D_{0} \mu d t\right] \\
\quad=\frac{s I_{e}}{T}\left(-\frac{1}{2} M D_{0} \mu^{2}+\frac{1}{6} D_{0} \mu^{3}+\frac{1}{2} D_{0} \mu M^{2}\right) .
\end{array}
$$

Case $2.3\left(\mu \leq M \leq t_{1} \leq T\right)$. The annual interest charged for the inventory not being sold after the due date $M$ is given by

$$
\begin{aligned}
\frac{c_{p} I_{c}}{T}\left[\int_{M}^{t_{1}} I_{2}(t) d t+\int_{t_{1}}^{T} I_{3}(t) d t\right] & \\
=\frac{c_{p} I_{c}}{T}( & -\frac{1}{3} D_{0} t_{1}^{3}+\frac{1}{3} D_{0} M^{3}-\frac{1}{2} D_{0} \mu^{2} M \\
& \left.\quad-D_{0} \mu T M+D_{0} \mu^{2} M+D_{0} \mu T^{2}-\frac{1}{2} D_{0} \mu^{2} T\right) .
\end{aligned}
$$

The annual interest earned during the trade credit period is shown in the following:

$$
\begin{array}{r}
\frac{s I_{e}}{T}\left[\int_{0}^{\mu}(M-t) D_{0} t d t+\int_{\mu}^{M}(M-t) D_{0} \mu d t\right] \\
\quad=\frac{s I_{e}}{T}\left(-\frac{1}{2} M D_{0} \mu^{2}+\frac{1}{6} D_{0} \mu^{3}+\frac{1}{2} D_{0} \mu M^{2}\right) .
\end{array}
$$

\subsubsection{Case 3: The Inventory Models for the Case $T<M$}

Case $3.1\left(t_{1} \leq \mu \leq T<M\right)$. The annual interest charged for the inventory not being sold after the due date $M$ is zero.

The annual interest earned during the trade credit period is shown in the following:

$$
\begin{aligned}
& \frac{s I_{e}}{T}\left[\int_{0}^{T}(M-t) D_{0} t d t+\int_{0}^{\bar{t}_{1}} K(t)(M-T) d t\right] \\
& \quad=\frac{s I_{e}}{T}\left[\frac{1}{2} M D_{0} T^{2}-\frac{1}{3} D_{0} T^{3}+r D_{0}(M-T) \frac{1}{2} \bar{t}_{1}^{2}\right] .
\end{aligned}
$$


Discrete Dynamics in Nature and Society

9

Case $3.2\left(\mu \leq t_{1} \leq T<M\right)$. The annual interest charged for the inventory not being sold after the due date $M$ is zero.

The annual interest earned during the trade credit period is shown in the following:

$$
\begin{gathered}
\frac{s I_{e}}{T}\left[\int_{0}^{T}(M-t) D_{0} t d t+\int_{0}^{t_{1}} K(t)(M-T) d t\right] \\
\quad=\frac{s I_{e}}{T}\left[\frac{1}{2} M D_{0} T^{2}-\frac{1}{3} D_{0} T^{3}+r D_{0}(M-T) \frac{1}{2} \mu^{2}\right. \\
\left.+r D_{0}(M-T)\left(t_{1}-\mu\right)\right] .
\end{gathered}
$$

5.4. The Optimal Replenishment Policy for the Model 2. Combine the inventory models of Cases 2 and 3, the results in previous subsections lead to the following total cost function.

(1) If $(1 / 2)(r+1) \mu \geq M \geq \mu$

$\operatorname{TRC}_{2}(T)$

$$
= \begin{cases}T R C_{31}, & t_{1} \leq \mu \leq T \leq M, \text { that is } \mu \leq T \leq M \\ T R C_{21}, & t_{1} \leq \mu \leq M \leq T, \\ & \text { that is } M \leq T \leq \frac{1}{2}(r+1) \mu \\ & \text { that is } \frac{1}{2}(r+1) \mu \leq T \leq M r-\frac{1}{2}(r-1) \mu \\ T R C_{23}, & \mu \leq M \leq t_{1} \leq T, \\ & \text { that is } M r-\frac{1}{2}(r-1) \mu \leq T .\end{cases}
$$

(2) If $(1 / 2)(r+1) \mu \leq M$

$\operatorname{TRC}_{2}(T)$

$$
= \begin{cases}T R C_{31}, & t_{1} \leq \mu \leq T \leq M, \text { that is } \mu \leq T \leq \frac{1}{2} \\ T R C_{32}, & \mu \leq t_{1} \leq T \leq M, \\ & \text { that is } \frac{1}{2}(r+1) \mu \leq T \leq M \\ T R C_{22}, & \mu \leq t_{1} \leq M \leq T, \\ & \text { that is } M \leq T \leq M r-\frac{1}{2}(r-1) \mu \\ T R C_{23}, & \mu \leq M \leq t_{1} \leq T, \\ & \text { that is } M r-\frac{1}{2}(r-1) \mu \leq T,\end{cases}
$$

where

$T_{R} C_{21}$

$$
\begin{gathered}
=\frac{A}{T}+\frac{c_{h}}{T}\left(\frac{1}{6} r D_{0} \bar{t}_{1}^{3}-\frac{1}{6} D_{0} \mu^{3}+\frac{1}{2} D_{0} \mu^{2} \bar{t}_{1}\right. \\
\left.\quad-D_{0} \mu T \bar{t}_{1}+\frac{1}{2} D_{0} \mu T^{2}\right) \\
+\frac{c_{p} I_{c}}{T}\left(\frac{1}{2} D_{0} \mu T^{2}-D_{0} \mu T M+\frac{1}{2} D_{0} \mu M^{2}\right) \\
-\frac{s I_{e}}{T}\left(-\frac{1}{2} M D_{0} \mu^{2}+\frac{1}{6} D_{0} \mu^{3}+\frac{1}{2} D_{0} \mu M^{2}\right) ;
\end{gathered}
$$

$\mathrm{TRC}_{22}$

$$
\begin{gathered}
=\frac{A}{T}+\frac{c_{h}}{T}\left[(r-1) \frac{1}{6} D_{0} \mu^{3}+\frac{1}{2} D_{0} \mu^{2} t_{1}\right. \\
\left.\quad+\frac{1}{2} D_{0} \mu T^{2}-D_{0} \mu t_{1} T\right] \\
+\frac{c_{p} I_{c}}{T}\left(\frac{1}{2} D_{0} \mu T^{2}-D_{0} \mu T M+\frac{1}{2} D_{0} \mu M^{2}\right) \\
-\frac{s I_{e}}{T}\left(-\frac{1}{2} M D_{0} \mu^{2}+\frac{1}{6} D_{0} \mu^{3}+\frac{1}{2} D_{0} \mu M^{2}\right) ;
\end{gathered}
$$

$\mathrm{TRC}_{23}$

$$
\begin{aligned}
& =\frac{A}{T}+\frac{c_{h}}{T}\left[(r-1) \frac{1}{6} D_{0} \mu^{3}+\frac{1}{2} D_{0} \mu^{2} t_{1}\right. \\
& \left.\quad+\frac{1}{2} D_{0} \mu T^{2}-D_{0} \mu t_{1} T\right] \\
& +\frac{c_{p} I_{c}}{T}\left(-\frac{1}{3} D_{0} t_{1}^{3}+\frac{1}{3} D_{0} M^{3}\right. \\
& \left.\quad+\frac{1}{2} D_{0} \mu^{2} M-D_{0} \mu T M+D_{0} \mu T^{2}-\frac{1}{2} D_{0} \mu^{2} T\right) \\
& -\frac{s I_{e}}{T}\left(-\frac{1}{2} M D_{0} \mu^{2}+\frac{1}{6} D_{0} \mu^{3}+\frac{1}{2} D_{0} \mu M^{2}\right)
\end{aligned}
$$

$\operatorname{TRC}_{31}$

$$
\begin{aligned}
& =\frac{A}{T}+\frac{c_{h}}{T}\left(\frac{1}{6} r D_{0} \bar{t}_{1}^{3}-\frac{1}{6} D_{0} \mu^{3}+\frac{1}{2} D_{0} \mu^{2} \bar{t}_{1}\right. \\
& \left.\quad-D_{0} \mu T t_{1}+\frac{1}{2} D_{0} \mu T^{2}\right) \\
& \quad-\frac{s I_{e}}{T}\left(\frac{1}{2} M D_{0} T^{2}-\frac{1}{3} D_{0} T^{3}+r D_{0}(M-T) \frac{1}{2} \bar{t}_{1}^{2}\right) ;
\end{aligned}
$$

$\mathrm{TRC}_{32}$

$$
=\frac{A}{T}+\frac{c_{h}}{T}\left[(r-1) \frac{1}{6} D_{0} \mu^{3}+\frac{1}{2} D_{0} \mu^{2} t_{1}\right.
$$




$$
\begin{gathered}
\left.+\frac{1}{2} D_{0} \mu T^{2}-D_{0} \mu t_{1} T\right] \\
-\frac{s I_{e}}{T}\left[\frac{1}{2} M D_{0} T^{2}-\frac{1}{3} D_{0} T^{3}+r D_{0}(M-T) \frac{1}{2} \mu^{2}\right. \\
\left.+r D_{0}(M-T)\left(t_{1}-\mu\right)\right] .
\end{gathered}
$$

In order to obtain the optimal replenishment decisions, we should study each branch of the cost functions.

Theorem 2. (1) If $\beta<0, T R C_{23}(T)$ is a convex function of $T$ for $T=(0, \infty)$. The optimal value of $T_{23}$ corresponds to $\min \left\{\operatorname{TRC}_{23}\left(\widetilde{T}_{23}\right), T R C_{23}(M r-(1 / 2)(r-1) \mu)\right\}$.

(2) If $\beta \geq 0, T R C_{23}(T)$ is an increasing function with $T$ for $T=(0, \infty)$. For $T \in[M r-(1 / 2)(r-1) \mu, \infty)$, the optimal value $T_{23}$ is obtained by $T_{23}=M r-(1 / 2)(r-1) \mu$.

It is similar to analyze the optimal solutions for other branches as Theorem 2. Based on the discussion, the solution procedure for determining the optimal replenishment cycle and the order quantity in the model 2 with $M \geq \mu$ can be summarized into the following algorithm.

\section{Algorithm 2.}

Step 1. Input the values for all parameters with $M \geq \mu$.

Step 2. Compare $(r+1) \mu / 2$ and $M$. If $(r+1) \mu / 2 \geq M \geq \mu$, go to Algorithm 2.1; if $M \geq(r+1) \mu / 2$, then go to Algorithm 2.2.

\section{Algorithm 2.1}

Step 1. Find the global minimum of $T R C_{31}(T)$, says $T_{31}$, as following.

Step 1.1. Compute $\widetilde{T}_{31}$, if $\mu \leq \widetilde{T}_{31} \leq M$ and $f_{31}^{\prime \prime}\left(\widetilde{T}_{31}\right)>0$, find the $\min \left\{T R C_{31}\left(\widetilde{T}_{31}\right), T R C_{31}(\mu), T R C_{31}(M)\right\}$ and accordingly set $T_{31}$. Compute $Q_{31}$ and $T R C_{31}\left(T_{31}\right)$. Else, go to Step 1.2.

Step 1.2. Find the $\min \left\{T R C_{31}(\mu), T R C_{31}(M)\right\}$ and accordingly set $T_{31}$. Compute $Q_{31}$ and $T R C_{31}\left(T_{31}\right)$.

Step 2. Find the global minimum of $T R C_{21}(T)$, says $T_{21}$, as follows.

Step 2.1. Compute $\widetilde{T}_{21}$, if $M \leq \widetilde{T}_{21} \leq(r+1) \mu / 2$ and $f_{21}^{\prime \prime}\left(\widetilde{T}_{21}\right)>$ 0 , find the $\min \left\{\operatorname{TRC}_{21}\left(\widetilde{T}_{21}\right), T R C_{21}(M), T R C_{21}((r+1) \mu / 2)\right\}$ and accordingly set $T_{21}$. Compute $Q_{21}$ and $T R C_{21}\left(T_{21}\right)$. Else, go to Step 2.2.

Step 2.2. Find the $\min \left\{T R C_{21}(M), T R C_{21}((r+1) \mu / 2)\right\}$ and accordingly set $T_{21}$. Compute $Q_{21}$ and $T R C_{21}\left(T_{21}\right)$.

Step 3. Find the global minimum of $T R C_{22}(T)$, says $T_{22}$, as follows.

Step 3.1. Compute $\widetilde{T}_{22}$, if $(r+1) \mu / 2 \leq \widetilde{T}_{22} \leq M r-(r+$ $1) \mu / 2$ and $f_{22}^{\prime \prime}\left(\widetilde{T}_{22}\right)>0$, find the $\min \left\{T R C_{22}\left(\widetilde{T}_{22}\right), T R C_{22}((r+\right.$
1) $\left.\mu / 2), T R C_{22}(M r-(r+1) \mu / 2)\right\}$ and accordingly set $T_{22}$. Compute $Q_{22}$ and $T R C_{22}\left(T_{22}\right)$. Else, go to Step 3.2.

Step 3.2. Find the $\min \left\{T R C_{22}((r+1) \mu / 2), T R C_{22}(M r-\right.$ $(r+1) \mu / 2)\}$ and accordingly set $T_{22}$. Compute $Q_{22}$ and $\operatorname{TRC}_{22}\left(T_{22}\right)$.

Step 4. Find the global minimum of $T R C_{23}(T)$, says $T_{23}$, as follows.

Step 4.1. Compute $\widetilde{T}_{23}$, if $(r+1) \mu / 2 \leq \widetilde{T}_{23}$, and then set $T_{23}=$ $\widetilde{T}_{23}$. Compute $Q_{23}$ and $T R C_{23}\left(T_{23}\right)$. Else, go to Step 4.2.

Step 4.2. Set $T_{23}=(r+1) \mu / 2$. Compute $Q_{23}$ and $T R C_{23}\left(T_{23}\right)$.

Step 5. Find the $\min \left\{T R C_{31}\left(T_{21}\right), T R C_{21}\left(T_{21}\right), T R C_{22}\left(T_{22}\right)\right.$, $\left.T R C_{23}\left(T_{23}\right)\right\}$ and accordingly select the optimal value for $T_{2}$. Stop.

\section{Algorithm 2.2}

Step 1. Find the global minimum of $T R C_{31}(T)$, says $T_{31}$, as follows.

Step 1.1. Compute $\widetilde{T}_{31}$, if $\mu \leq \widetilde{T}_{31} \leq(r+1) \mu / 2$ and $f_{31}^{\prime \prime}\left(\widetilde{T}_{31}\right)>0$, find the $\min \left\{\operatorname{TRC}_{31}\left(\widetilde{T}_{31}\right), T R C_{31}(\mu), T R C_{31}((r+1) \mu / 2)\right\}$ and accordingly set $T_{31}$. Compute $Q_{31}$ and $T R C_{31}\left(T_{31}\right)$. Else, go to Step 1.2.

Step 1.2. Find the $\min \left\{T R C_{31}(\mu), T R C_{31}((r+1) \mu / 2)\right\}$ and accordingly set $T_{31}$. Compute $Q_{31}$ and $T R C_{31}\left(T_{31}\right)$.

Step 2. Find the global minimum of $T R C_{32}(T)$, says $T_{32}$, as follows.

Step 2.1. Compute $\widetilde{T}_{32}$, if $(r+1) \mu / 2 \leq \widetilde{T}_{32} \leq M$ and $f_{32}^{\prime \prime}\left(\widetilde{T}_{32}\right)>$ 0 , find the $\min \left\{T R C_{32}\left(\widetilde{T}_{32}\right), T R C_{32}((r+1) \mu / 2), T R C_{32}(M)\right\}$ and accordingly set $T_{32}$. Compute $Q_{32}$ and $T R C_{32}\left(T_{32}\right)$. Else, go to Step 2.2.

Step 2.2. Find the $\min \left\{T R C_{32}((r+1) \mu / 2), T R C_{32}(M)\right\}$ and accordingly set $T_{32}$. Compute $Q_{32}$ and $T R C_{32}\left(T_{32}\right)$.

Step 3. Find the global minimum of $T R C_{22}(T)$, says $T_{22}$, as follows.

Step 3.1. Compute $\widetilde{T}_{22}$, if $M \leq \widetilde{T}_{22} \leq M r-(r+$ $1) \mu / 2$ and $f_{22}^{\prime \prime}\left(\widetilde{T}_{22}\right)>0$, find the $\min \left\{T R C_{22}\left(\widetilde{T}_{22}\right)\right.$, $\left.T R C_{22}(M), T R C_{22}(M r-(r+1) \mu / 2)\right\}$ and accordingly set $T_{22}$. Compute $Q_{22}$ and $T R C_{22}\left(T_{22}\right)$. Else, go to Step 3.2.

Step 3.2. Find the $\min \left\{T R C_{22}(M), T R C_{22}(M r-(r+1) \mu / 2)\right\}$ and accordingly set $T_{22}$. Compute $Q_{22}$ and $T R C_{22}\left(T_{22}\right)$.

Step 4 . Find the global minimum of $T R C_{23}(T)$, says $T_{23}$, as follows.

Step 4.1. Compute $\widetilde{T}_{23}$, if $(r+1) \mu / 2 \leq \widetilde{T}_{23}$, and then set $T_{23}=$ $\widetilde{T}_{23}$. Compute $Q_{23}$ and $T R C_{23}\left(T_{23}\right)$. Else, go to Step 4.2.

Step 4.2. Set $T_{23}=(r+1) \mu / 2$. Compute $Q_{23}$ and $T R C_{23}\left(T_{23}\right)$.

Step 5. Find the $\min \left\{T R C_{31}\left(T_{21}\right), T R C_{32}\left(T_{32}\right), T R C_{22}\left(T_{22}\right)\right.$, $\left.T R C_{23}\left(T_{23}\right)\right\}$ and accordingly select the optimal value for $T_{2}$. Stop. 


\section{Numerical Examples and Sensitivity Analysis}

In this section, we carry out some numerical examples to illustrate the algorithms obtained in the previous sections. Additionally, we also provide a sensitivity analysis of the values of most important parameters on the optimal decisions of the retailer and the total cost.

\subsection{Numerical Examples}

Example $1(\mu / \sqrt{r} \leq M \leq \mu)$. The input parameters are $A=$ $\$ 50$ per order, $D_{0}=500$ units, $r=2, s=\$ 100$ per unit, $c_{h}=$ $\$ 5$ per unit per year, $c_{p}=\$ 40$ per unit, $I_{e}=0.15, I_{c}=0.08$, $M=0.3$ year, and $\mu=0.4$ year.

Using Algorithm 1, we can calculate $T R C_{11}\left(T_{11}\right)=351.8$ with $T_{11}=0.4, T R C_{12}\left(T_{12}\right)=393.2$ with $T_{12}=0.4250$, and $\operatorname{TRC}_{13}\left(T_{13}\right)=142.6$ with $T_{13}=0.6000$. Therefore, the optimal order cycle for the retailer is $T_{1}=T_{13}=0.6000$ year and the optimal order quantity is $Q_{1}=80$ units. The minimum of the total cost is $T R C_{1}=\$ 142.6$.

Example $2(0 \leq M \leq \mu / \sqrt{r})$. The input parameters are $A=$ $\$ 50$ per order, $D_{0}=500$ units, $r=2, s=\$ 100$ per unit, $c_{h}=$ $\$ 5$ per unit per year, $c_{p}=\$ 40$ per unit, $I_{e}=0.15, I_{c}=0.08$, $M=0.2$ year, and $\mu=0.4$ year.

Using Algorithm 1, we can calculate $T R C_{12}\left(T_{12}\right)=441.6$ with $T_{12}=0.4000$, and $T R C_{13}\left(T_{13}\right)=190.7$ with $T_{13}=$ 0.6000 . Therefore, the optimal order cycle for the retailer is $T_{1}=T_{13}=0.6000$ year and the optimal order quantity is $Q_{1}=80$ units. The minimum of the total cost is $T R C_{1}=$ $\$ 190.7$.

Example $3((r+1) \mu / 2 \geq M \geq \mu)$. The input parameters are $A=\$ 50$ per order, $D_{0}=500$ units, $r=2, s=\$ 40$ per unit, $c_{h}=\$ 5$ per unit per year, $c_{p}=\$ 20$ per unit, $I_{e}=0.15, I_{c}=$ $0.08, M=0.6$ year, and $\mu=0.4$ year.

Using Algorithm 2, we can calculate $T R C_{31}\left(T_{31}\right)=92.3$ with $T_{31}=0.4000, T R C_{21}\left(T_{21}\right)=347.0$ with $T_{21}=0.6000$, $T R C_{22}\left(T_{22}\right)=107.2$ with $T_{22}=0.8000$, and $T R C_{23}\left(T_{23}\right)=$ 533.2 with $T_{23}=1.4$. Therefore, the optimal order cycle for the retailer is $T_{1}=T_{31}=0.4000$ year and the optimal order quantity is $Q_{1}=40$ units. The minimum of the total cost is $T R C_{2}=\$ 92.3$.

Example $4((r+1) \mu / 2 \leq M)$. The input parameters are $A=$ $\$ 50$ per order, $D_{0}=500$ units, $r=2, s=\$ 40$ per unit, $c_{h}=$ $\$ 5$ per unit per year, $c_{p}=\$ 20$ per unit, $I_{e}=0.15, I_{c}=0.08$, $M=0.9$ year, and $\mu=0.4$ year.

Using Algorithm 2, we can calculate $T R C_{31}\left(T_{31}\right)=576.1$ with $T_{31}=0.6367, T R C_{32}\left(T_{32}\right)=261.7$ with $T_{32}=0.8000$, $T R C_{22}\left(T_{22}\right)=416.3$ with $T_{22}=0.9000$, and $T R C_{23}\left(T_{23}\right)=$ 1140.1 with $T_{23}=2.3$. Therefore, the optimal order cycle for the retailer is $T_{1}=T_{31}=0.4000$ year and the optimal order quantity is $Q_{1}=120$ units. The minimum of the total cost is $T R C_{2}=\$ 261.7$.

6.2. Sensitivity Analysis. In the model, there are many parameters influencing the decisions of the members. But according to the past research, the effects of some parameters on the decisions are analyzed in many literatures such as the ordering cost per order. Therefore, we choose three parameters, which are directly related to our innovations, to conduct the sensitivity analysis for obtaining interesting management insights. In this subsection, we present the sensitivity analysis of the models mentioned above with respect to the three parameters of $r, M$, and $\mu$.

6.2.1. The Impact of the Changes of the Parameter $r$. Basic parameters' values for the case $M \leq \mu$ are $A=\$ 50$ per order, $D_{0}=500$ units, $s=\$ 100$ per unit, $c_{h}=\$ 5$ per unit per year, $c_{p}=\$ 40$ per unit, $I_{e}=0.15, I_{c}=0.08, M=0.3$ year, and $\mu=0.6$ year. The impacts of the changes of the parameter $r$ on the retailer' decisions and cost are shown in Figure 6.

Basic parameters' values for the case $M \geq \mu$ are $A=\$ 250$ per order, $D_{0}=500$ units, $s=\$ 40$ per unit, $c_{h}=\$ 5$ per unit per year, $c_{p}=\$ 20$ per unit, $I_{e}=0.15, I_{c}=0.08, M=0.7$ year, and $\mu=0.3$ year. The impacts of the changes of the parameter $r$ on the retailer' decisions and its cost are shown in Figure 7.

Based on Figures 6 and 7, we can see that if the demand dependent production rate is lower, as the increasing of the parameter $r$, the optimal order cycle and the optimal order quantity are increasing. It means that if the value of production rate is small, the retailer will lower the frequency of putting the orders to cut down the order cost. If the demand dependent rate is higher, the demand dependent production rate has no effect on the optimal order cycle and the order quantity. For the limit case, when the production rate is infinite, as most papers presented, the production rate has no influence on the members' decisions.

For the total cost, as the increase of the parameter $r$, the total cost is first increasing and then decreasing with this parameter. It demonstrated that when the value of production rate is small, the on-hand inventory level is low, which results in low total cost. When the demand dependent production rate is much higher, the retailer's profit is decreasing with this rate, because the retailer can get the products as soon as possible to better meet the demand of the market; on the other hand, in general, there is not shortage to occur for the retailer, which will save the shortage cost for the retailer.

6.2.2. The Impact of the Changes of the Parameter M. Basic parameters' values are $A=\$ 250$ per order, $D_{0}=500$ units, $s=\$ 40$ per unit, $c_{h}=\$ 5$ per unit per year, $c_{p}=\$ 20$ per unit, $I_{e}=0.15, I_{c}=0.08, r=2$, and $\mu=0.5$ year.

Based on Figure 8, we can see that as the delayed payment time offered by the suppliers is increasing till $M=\mu$, the optimal order cycle and the optimal order quantity are nonincreasing, which demonstrate that when the delayed payment time is less than the growth stage time of the 


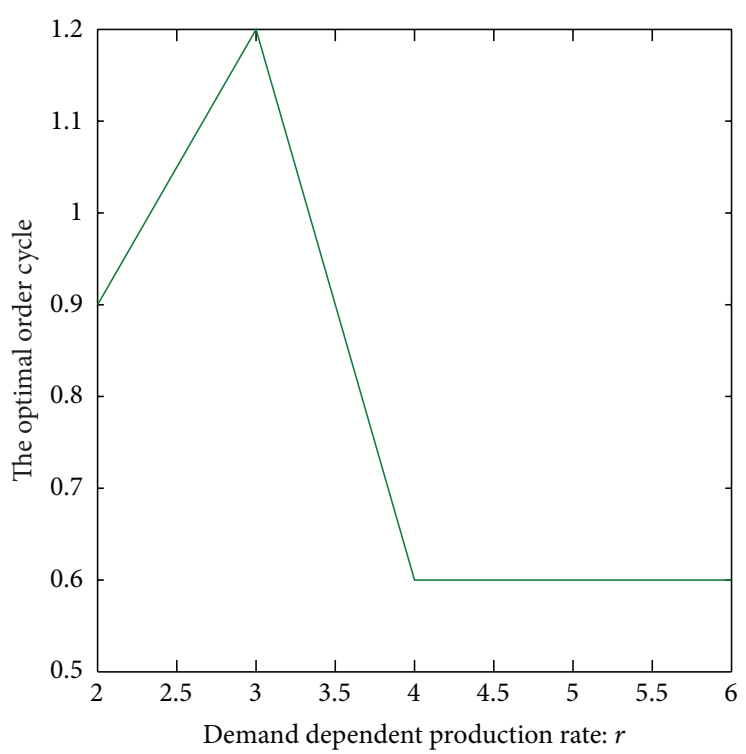

(a) The optimal order cycle

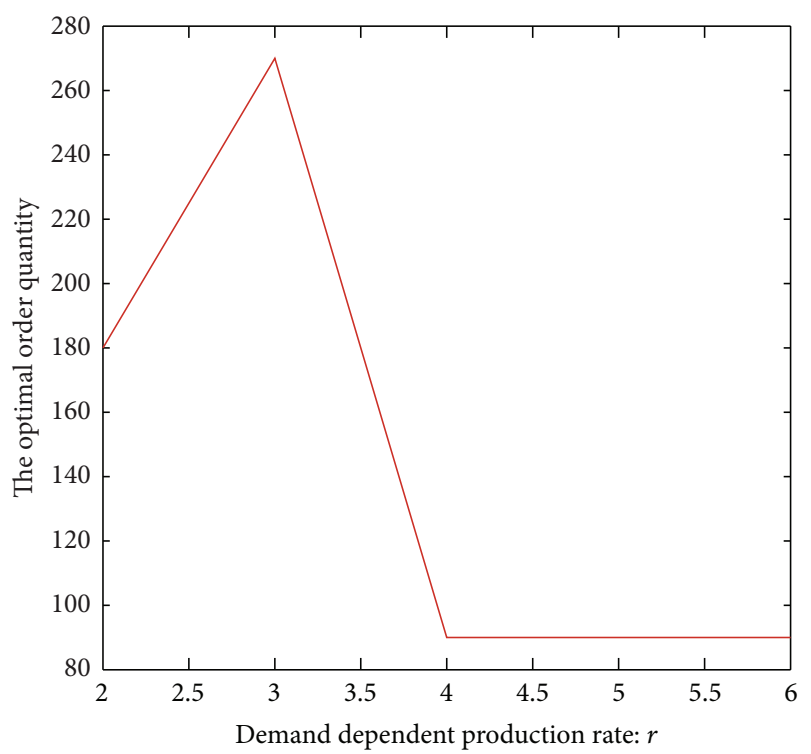

(b) The optimal order quantity

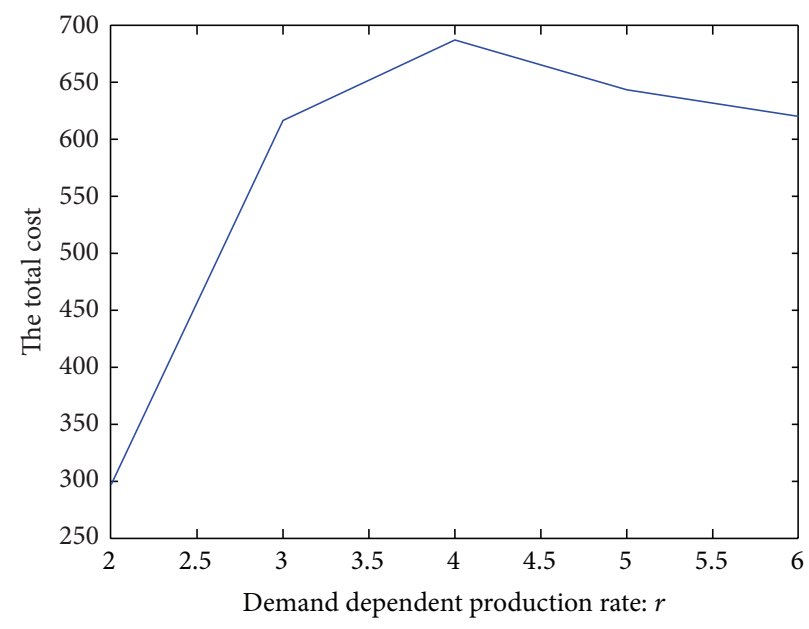

(c) The total cost for the retailer

FIgURE 6: The impact of the changes of the parameter $r$ when $M \leq \mu$.

new products' introduction, the retailer will shorten the replenishment cycle to take advantage of the trade credit more frequently for accumulating the interest; on the other hand, the short order cycle can make the retailer adjust its order decisions more quickly for meeting the changeable demand within the growth stage of the products.

When $M>\mu$, that is, the delayed payment time is larger than the breakpoint of the demand, during the maturity stage of the products, the delayed payment time has no effect on the optimal order cycle and the optimal order quantity. Therefore, during the maturity stage of the new products, the retailer's replenishment policies are not influenced by the delayed payment time offered by the supplier.

However, the total cost for the retailer is decreasing with the delayed payment time for the product life cycle.
Therefore, the retailer hopes the supplier can offer them the delayed payment time as long as possible to obtain more profits.

6.2.3. The Impact of the Changes of the Parameter $\mu$. Basic parameters' values are $A=\$ 250$ per order, $D_{0}=500$ units, $s=\$ 40$ per unit, $c_{h}=\$ 5$ per unit per year, $c_{p}=\$ 20$ per unit, $I_{e}=0.15, I_{c}=0.08, r=2$, and $M=0.5$ year.

Based on Figure 9, we can see that as the demand breakpoint is increasing; the optimal order cycle and the optimal order quantity are decreasing at short time firstly and then increasing for the last time. That is, when the breakpoint is large, the new products moving to the maturity period at slow speed, the demand is changed slowly. Therefore, in 


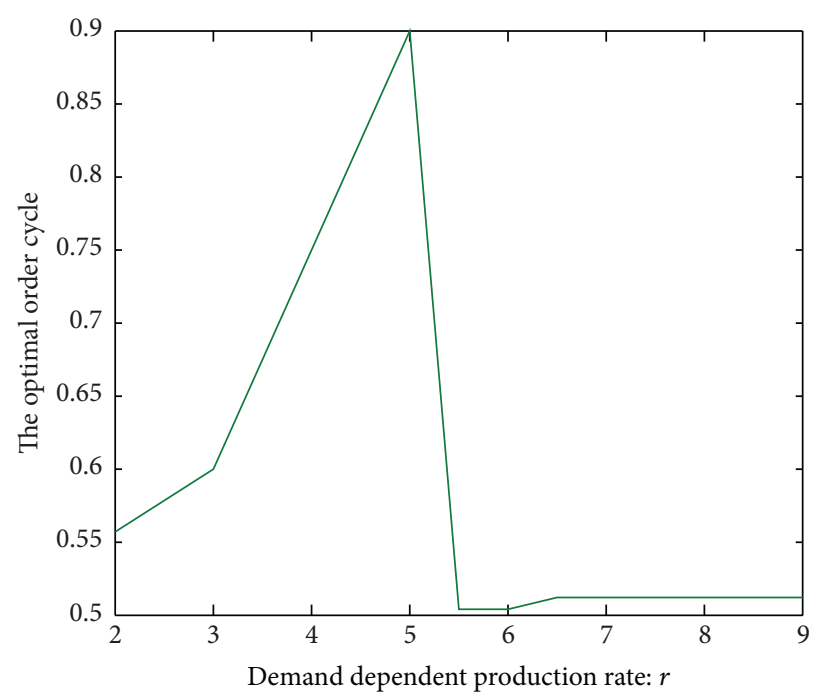

(a) The optimal order cycle

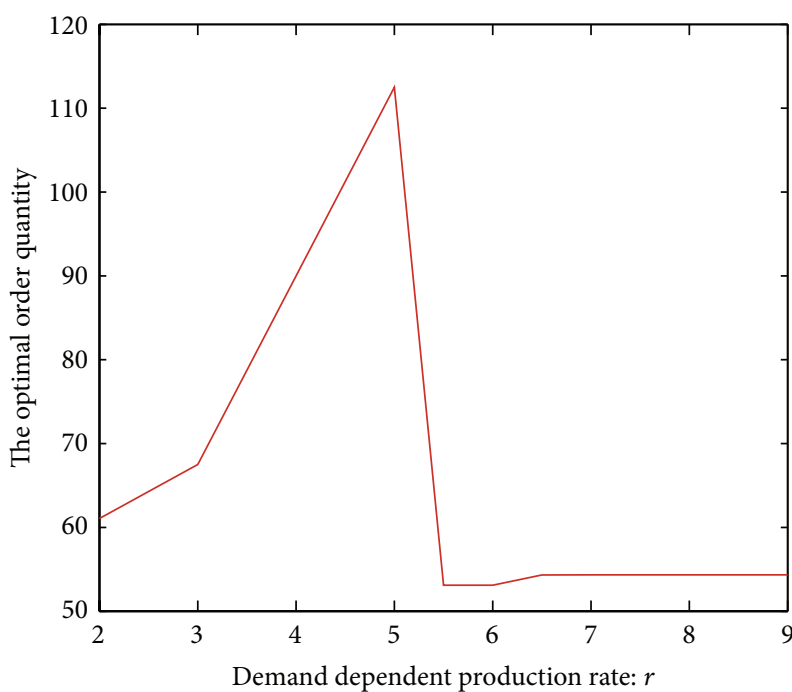

(b) The optimal order quantity

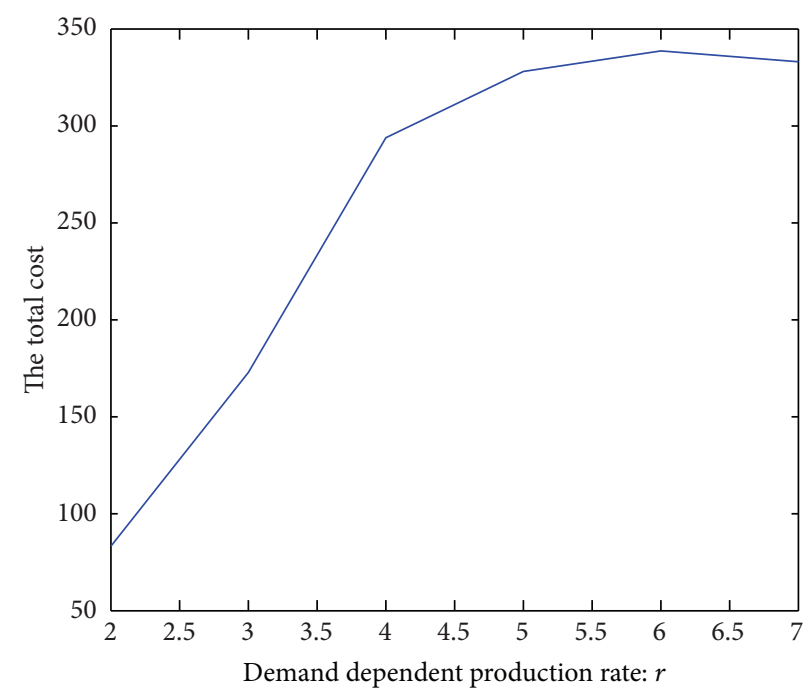

(c) The total cost for the retailer

FIGURE 7: The impact of the changes of the parameter $r$ when $M \geq \mu$.

the relative stable market, the retailer can increase the order quantity and replenishment cycle to lower the cost.

The total cost for the retailer is increasing with the demand breakpoint. Hence, for the products, if the growth stage of the product life cycle is longer, the cost of the retailer will be higher. Therefore, the retailer should make some measures, such as advertisement, to induce the products' demand moving to the maturity stage as soon as possible.

\section{Conclusions}

Most of the existing inventory models under trade credit financing are assumed that the demand is a constant and the replenishment rate is infinite or a constant. However, in practice, the demand rate is the ramp type function of time for some cases, such as the new products and the holiday related products. On the other hand, the production rate is related to the market demand. When the market is better, the production rate will be improved. When the retailer makes an order, it can be met faster. That is, the replenishment of the retailer is related to the market demand.

Therefore, in this paper, we developed an EOQ model under trade credit financing with ramp type demand and the demand dependent production rate. Subsequently, the algorithms are proposed to decide the optimal replenishment cycle and the optimal order quantity for the retailer. Finally, the numerical analysis is demonstrated to illustrate the models and the sensitively analysis is carried out to give some management insights.

Based on the study, we mainly found the following.

(1) If the value of production rate is small, the retailer will lower the frequency of putting the orders to cut down 


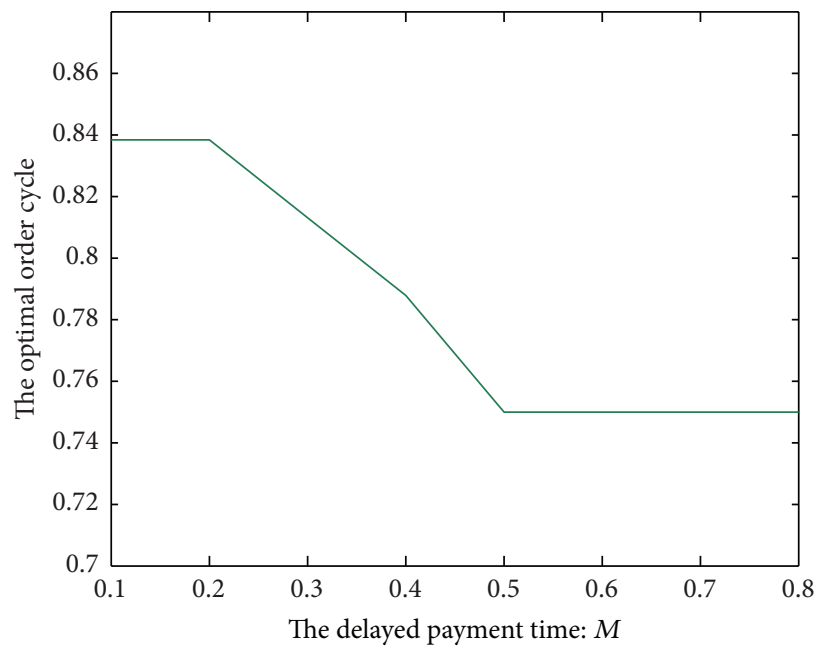

(a) The optimal order cycle

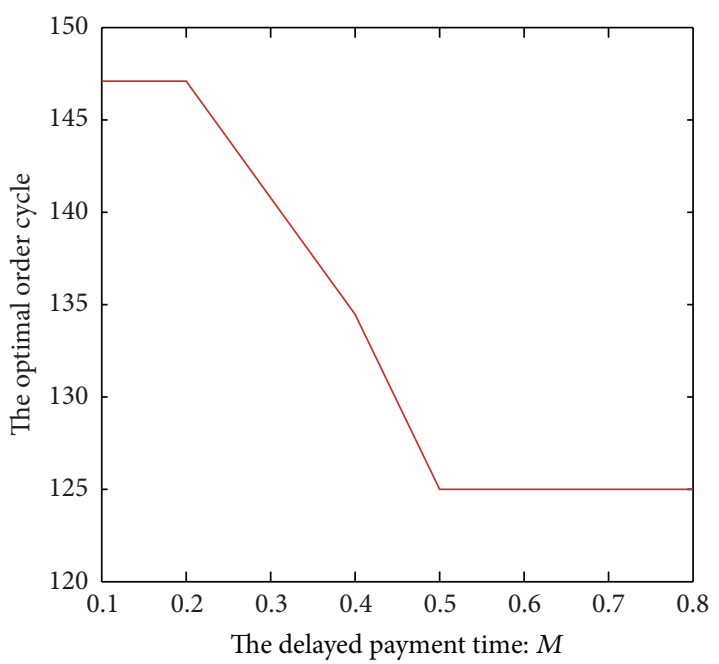

(b) The optimal order quantity

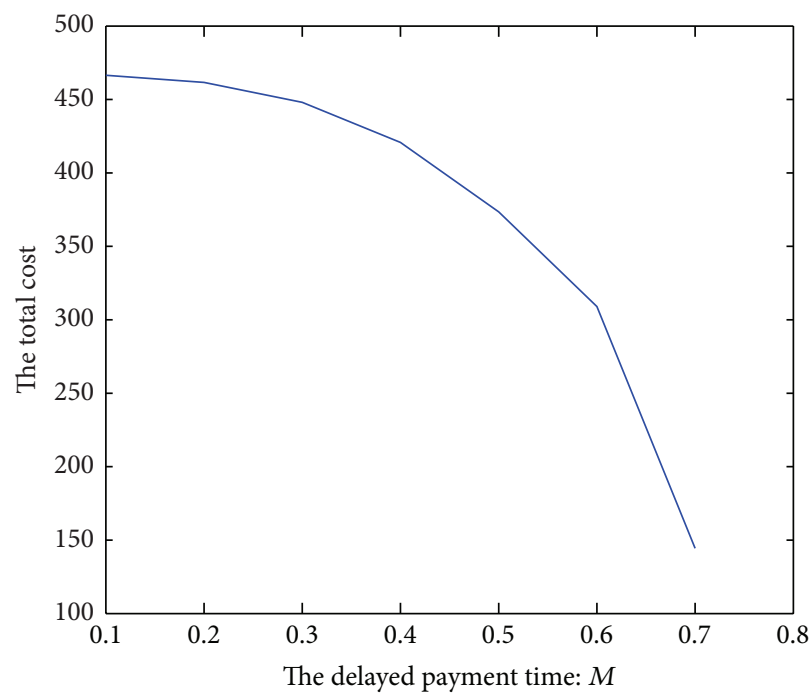

(c) The total cost for the retailer

FIgURE 8: The impact of the changes of the parameter $M$.

the order cost. If the demand dependent rate is higher, the demand dependent production rate has no effect on the optimal order cycle and the order quantity. For the limit case, when the production rate is infinite, as most papers presented, the production rate has no influence on the members' decisions.

(2) When the delayed payment time is less than the growth stage time of the new products' introduction, the retailer will shorten the replenishment cycle to take advantage of the trade credit more frequently for accumulating the interest; on the other hand, the short order cycle can make the retailer adjust its order decisions more quickly for meeting the changeable demand within the growth stage of the products.
When the delayed payment time is larger than the breakpoint of the demand, within the maturity stage of the products, the delayed payment time has no effect on the optimal order cycle and the optimal order quantity. The total cost for the retailer is decreasing with the delayed payment time. Therefore, the retailer hopes the supplier can offer them the delayed payment time as long as possible.

(3) As the demand breakpoint is increasing, the optimal order cycle and the optimal order quantity are decreasing first and then increasing. The total cost for the retailer is increasing with the demand breakpoint. Hence, for the products, if the growth stage of the product life cycle is longer, the cost of the retailer 


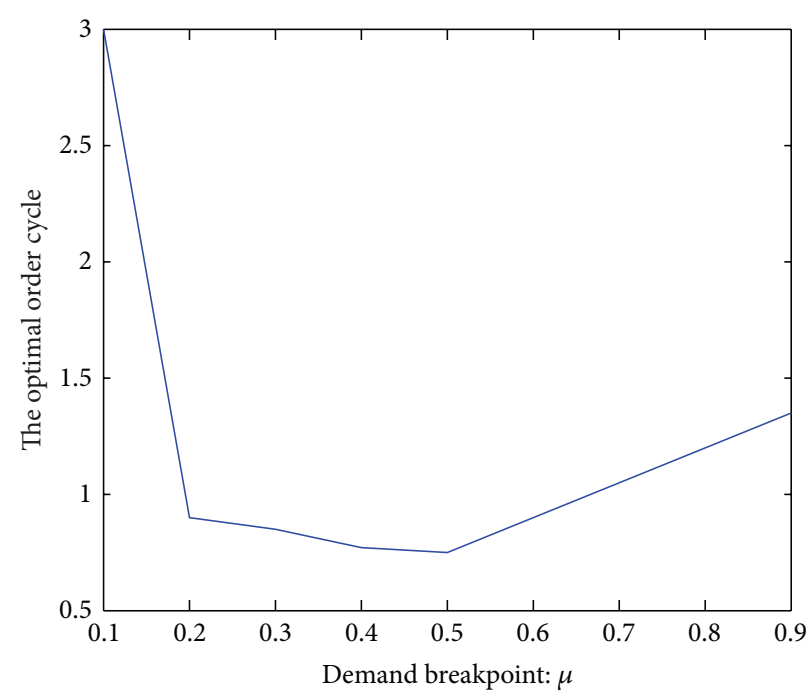

(a) The optimal order cycle

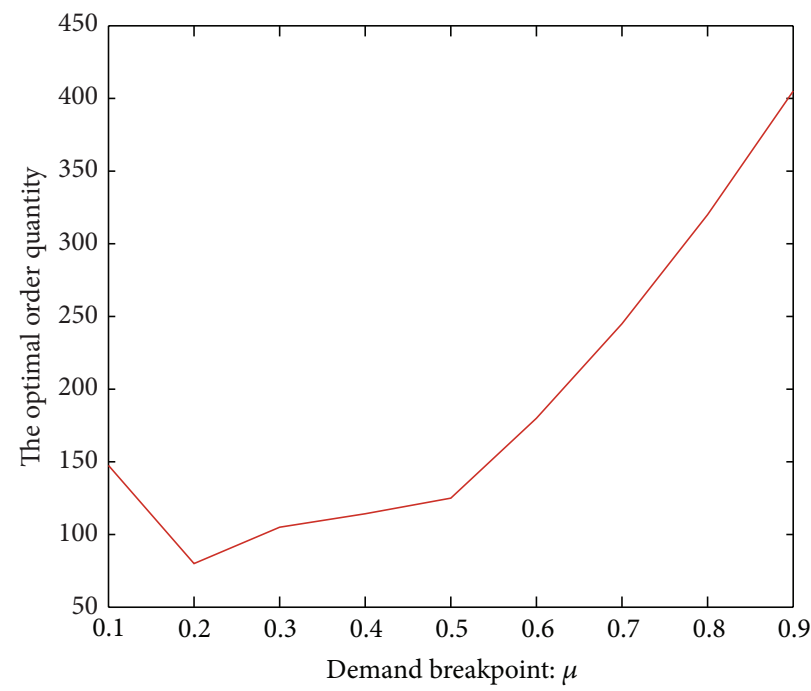

(b) The optimal order quantity

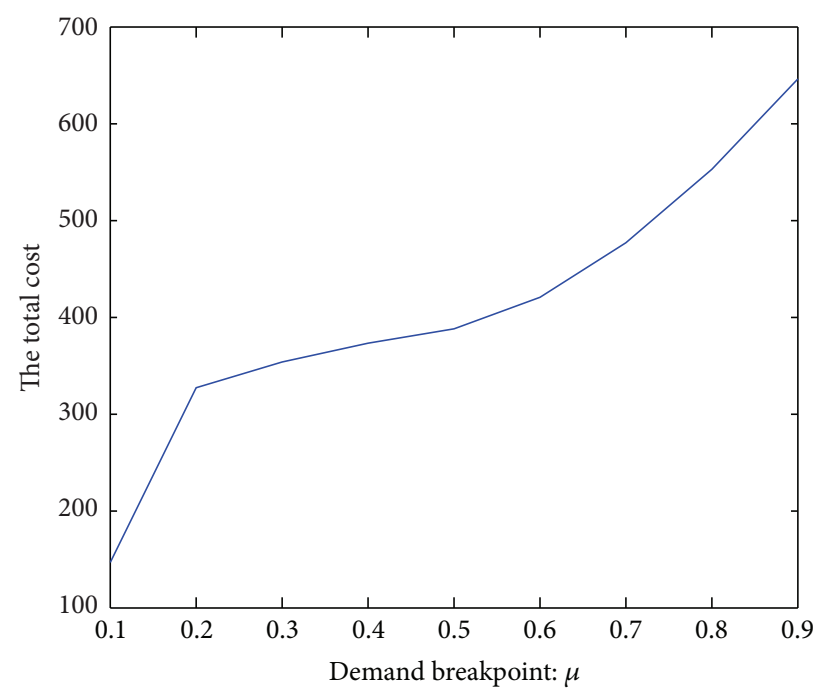

(c) The total cost for the retailer

FIGURE 9: The impact of the changes of the parameter $\mu$.

will be higher. Therefore, the retailer should make some measures, such as advertisement, to induce the products' demand moving to the maturity stage as soon as possible.

The research presented in this paper can be extended in several ways. For example, other demand functions can be further discussed considering the demand dependent production rate in the EOQ inventory model with the trade credit financing. Additionally, the models can be generalized to consider the shortage or the partial backlogging. Furthermore, the influence of the poor quality products on the EOQ model can be discussed to obtain some management insights.

\section{Appendices}

\section{A. Proof of Theorem 1}

The first derivative for a minimum of $T R C_{13}$ is

$$
\frac{\partial T R C_{13}}{\partial T}=-\frac{1}{T^{2}} f_{13}(T)+\frac{1}{T} f_{13}^{\prime}(T)
$$

with

$$
\begin{aligned}
f_{13}(T)=A & +\left(c_{h}+c_{p} I_{c}\right) \\
\times & {\left[(r-1) \frac{1}{6} D_{0} \mu^{3}+\frac{1}{2} D_{0} \mu^{2} t_{1}\right.} \\
& \left.\quad+\frac{1}{2} D_{0} \mu T^{2}-D_{0} \mu t_{1} T\right]
\end{aligned}
$$




$$
\begin{aligned}
& -\frac{1}{6} c_{p} I_{c}(r-1) D_{0} M^{3}-\frac{s I_{e}}{6} D_{0} M^{3}, \\
f_{13}^{\prime}(T)= & \left(c_{h}+c_{p} I_{c}\right) \\
& \times\left[-\frac{1}{2 r}(r-1) D_{0} \mu^{2}+D_{0} \mu T\left(\frac{r-1}{r}\right)\right] ; \\
f_{13}^{\prime \prime}(T)= & \left(c_{p} I_{c}+c_{h}\right) D_{0} \mu \frac{r-1}{r} .
\end{aligned}
$$

Based on (A.1), we have

$$
\begin{aligned}
\frac{\partial T R C_{13}}{\partial T} & \\
=\frac{1}{T^{2}}\{ & -A-\left(c_{h}+c_{p} I_{c}\right) \\
\times & {\left[(r-1) \frac{1}{6} D_{0} \mu^{3}-\frac{1}{8 r} D_{0}(r-1)^{2} \mu^{3}\right.} \\
& \left.-\frac{r-1}{2 r} D_{0} \mu T^{2}\right] \\
+ & \left.\frac{1}{6} c_{p} I_{c}(r-1) D_{0} M^{3}+\frac{s I_{e}}{6} D_{0} M^{3}\right\} .
\end{aligned}
$$

The second derivatives for $T R C_{13}$ with respect to $T$ is

$$
\begin{aligned}
& \frac{\partial^{2} T R C_{13}}{\partial T^{2}} \\
& =\frac{2}{T^{3}} f(T)-\frac{2}{T^{2}} f^{\prime}(T)+\frac{1}{T} f^{\prime \prime}(T) \\
& =\frac{-2}{T^{3}}\left\{-A-\left(c_{h}+c_{p} I_{c}\right)\right. \\
& \times\left[(r-1) \frac{1}{6} D_{0} \mu^{3}-\frac{1}{8 r} D_{0}(r-1)^{2} \mu^{3}\right] \\
& \left.+\frac{1}{6} c_{p} I_{c}(r-1) D_{0} M^{3}+\frac{s I_{e}}{6} D_{0} M^{3}\right\} .
\end{aligned}
$$

We can know that $\lim _{T \rightarrow \infty}\left(\partial T R C_{13} / \partial T\right)>0$.

Let us set

$$
\begin{aligned}
\alpha= & -A-\left(c_{h}+c_{p} I_{c}\right) D_{0} \mu^{3}(r-1)\left(\frac{1}{24}+\frac{1}{8 r}\right) \\
& +\frac{1}{6} D_{0} M^{3}\left(c_{p} I_{c}(r-1)+s I_{e}\right) .
\end{aligned}
$$

If $\alpha<0$, then $\lim _{T \rightarrow 0}\left(\partial T R C_{13} / \partial T\right)<0$. Therefore, the intermediate value theorem yields that there exists $\widetilde{T}_{13}$ as the root of $\partial T R C_{13} / \partial T=0$ for $T=(0, \infty)$. And when $\alpha<0$, we have $\partial^{2} T R C_{13} / \partial T^{2}>0$. This $\widetilde{T}_{13}$ not only exits but also is unique. If $\widetilde{T}_{13}$ is feasible, that is $(1 / 2)(r+1) \mu \leq \widetilde{T}_{13}$ for (22) and (23), the optimal replenishment cycle is $T_{13}=\widetilde{T}_{13}$. Otherwise, if $\widetilde{T}_{13}$ is infeasible, the optimal replenishment cycle is $T_{13}=$ $(1 / 2)(r+1) \mu$. The optimal value of the order level is $Q_{13}=$ $\int_{0}^{\mu} D_{0} t d t+\int_{\mu}^{T_{13}} D_{0} \mu d t$.
If $\alpha \geq 0$, then $\partial T R C_{13} / \partial T>0 . T R C_{13}$ is an increasing function with $T$ for $T=(0, \infty)$. For $T \in[(1 / 2)(r+1) \mu, \infty)$, the optimal value $T_{13}$ is obtained when $T=(1 / 2)(r+1) \mu$. The optimal value of the order level is $Q_{13}=\int_{0}^{\mu} D_{0} t d t+$ $\int_{\mu}^{T_{13}} D_{0} \mu d t$.

Based on the analysis above, it is easy to obtain Theorem 1.

\section{B. Proof of Theorem 2}

Calculate the first derivatives of the $T R C_{23}$ with respect to $T$ :

$$
\frac{\partial T R C_{23}}{\partial T}=-\frac{1}{T^{2}} f(T)+\frac{1}{T} f^{\prime}(T) ;
$$

with

$$
\begin{aligned}
& f_{23}(T)=A+c_{h}[(r-1) \frac{1}{6} D_{0} \mu^{3}+\frac{1}{2} D_{0} \mu^{2} t_{1} \\
&\left.+\frac{1}{2} D_{0} \mu T^{2}-D_{0} \mu t_{1} T\right] \\
&+c_{p} I_{c}(-\frac{1}{3} D_{0} t_{1}^{3}+\frac{1}{3} D_{0} M^{3}-\frac{1}{2} D_{0} \mu^{2} M \\
&-D_{0} \mu T M+D_{0} \mu^{2} M \\
&\left.+D_{0} \mu T^{2}-\frac{1}{2} D_{0} \mu^{2} T\right) \\
&- s I_{e}\left(-\frac{1}{2} M D_{0} \mu^{2}+\frac{1}{6} D_{0} \mu^{3}+\frac{1}{2} D_{0} \mu M^{2}\right), \\
& f_{23}^{\prime}(T)=c_{h}\left[-\frac{1}{2 r}(r-1) D_{0} \mu^{2}+D_{0} \mu T\left(\frac{r-1}{r}\right)\right] \\
&+c_{p} I_{c}\left(-2 D_{0} t_{1} \frac{1}{r^{2}}+2 D_{0} \mu\right) ; \\
& f_{23}^{\prime \prime}(T)=c_{h} D_{0} \mu \frac{r-1}{r}-2 c_{p} I_{c} \frac{1}{r^{3}} D_{0} .
\end{aligned}
$$

Therefore, we have

$$
\begin{aligned}
& \frac{\partial T R C_{23}}{\partial T} \\
&=\frac{1}{T^{2}}\left\{-A-c_{h}\right. \\
& \times\left[(r-1) \frac{1}{6} D_{0} \mu^{3}-\frac{1}{8 r} D_{0}(r-1)^{2} \mu^{3}\right. \\
&\left.\quad-\frac{r-1}{2 r} D_{0} \mu T^{2}\right]
\end{aligned}
$$




$$
\begin{aligned}
& +s I_{e}\left(-\frac{1}{2} M D_{0} \mu^{2}+\frac{1}{6} D_{0} \mu^{3}+\frac{1}{2} D_{0} \mu M^{2}\right) \\
& \left.-c_{p} I_{c}\left[\frac{1}{3} D_{0} M^{3}-\frac{1}{2} D_{0} \mu^{2} M+D_{0} \mu^{2} M\right]\right\} \\
& +c_{p} I_{c} D_{0} \mu .
\end{aligned}
$$

The second derivatives for $T R C_{23}$ with respect to $T$ is

$$
\begin{aligned}
\frac{\partial^{2} T R C_{23}}{\partial T^{2}} & \\
=-\frac{2}{T^{3}}\{ & -A-c_{h} \\
& \times\left[(r-1) \frac{1}{6} D_{0} \mu^{3}-\frac{1}{8 r} D_{0}(r-1)^{2} \mu^{3}\right] \\
& +s I_{e}\left(-\frac{1}{2} M D_{0} \mu^{2}+\frac{1}{6} D_{0} \mu^{3}+\frac{1}{2} D_{0} \mu M^{2}\right) \\
& \left.-c_{p} I_{c}\left[\frac{1}{3} D_{0} M^{3}-\frac{1}{2} D_{0} \mu^{2} M+D_{0} \mu^{2} M\right]\right\} .
\end{aligned}
$$

We know that $\lim _{T \rightarrow \infty}\left(\partial T R C_{23} / \partial T\right)>0$.

Let us set

$$
\begin{aligned}
\beta= & -A-c_{h} \\
& \times\left[(r-1) \frac{1}{6} D_{0} \mu^{3}-\frac{1}{8 r} D_{0}(r-1)^{2} \mu^{3}\right] \\
& +s I_{e}\left(-\frac{1}{2} M D_{0} \mu^{2}+\frac{1}{6} D_{0} \mu^{3}+\frac{1}{2} D_{0} \mu M^{2}\right) \\
& -c_{p} I_{c}\left[\frac{1}{3} D_{0} M^{3}-\frac{1}{2} D_{0} \mu^{2} M+D_{0} \mu^{2} M\right] .
\end{aligned}
$$

If $\beta<0$, then $\lim _{T \rightarrow 0}\left(\partial T R C_{23} / \partial T\right)<0$. Therefore, the intermediate value theorem yields that there exists $\partial T R C_{23} / \partial T=0$ for $T=(0, \infty)$. And when $\beta<0$, we have $\partial^{2} T R C_{23} / \partial T^{2}>0$. The optimal value of $\widetilde{T}_{23}$ can be obtained by solving the equation $\partial T R C_{23} / \partial T=0 . \widetilde{T}_{23}$ not only exits but also is unique. If $\widetilde{T}_{23}$ is feasible, that is, $M r-(1 / 2)(r-$ 1) $\mu \leq \widetilde{T}_{23}$ for (33) and (34), the optimal replenishment cycle $T_{23}=\widetilde{T}_{23}$. Otherwise, the optimal replenishment cycle is $T_{23}=M r-(1 / 2)(r-1) \mu$. The optimal order quantity is $Q_{23}=\int_{0}^{\mu} D_{0} t d t+\int_{\mu}^{T_{23}} D_{0} \mu d t$.

If $\beta \geq 0, \partial T R C_{23} / \partial T>0$, so $T R C_{23}$ is an increasing function with $T$ for $T=(0, \infty)$. For $M r-(1 / 2)(r-1) \mu \leq T$, the optimal value of $T_{23}$ can be obtained by $T=M r-$ $(1 / 2)(r-1) \mu$. The optimal order quantity is $Q_{23}=\int_{0}^{\mu} D_{0} t d t+$ $\int_{\mu}^{T_{23}} D_{0} \mu d t$

Based on the analysis above, it is easy to obtain Theorem 2.

\section{Conflict of Interests}

The authors declare that there is no conflict of interests regarding the publication of this paper.

\section{Acknowledgments}

The paper is funded by The National Natural Science Foundation of China (71302115, 71172018), The Ministry of education of Humanities, and Social Sciences Project (13YJC630121).

\section{References}

[1] K.-J. Chung and J.-J. Liao, "The simplified solution algorithm for an integrated supplier-buyer-inventory model with twopart trade credit in a supply chain system," European Journal of Operational Research, vol. 213, no. 1, pp. 156-165, 2011.

[2] Y.-C. Tsao and G.-J. Sheen, "Dynamic pricing, promotion and replenishment policies for a deteriorating item under permissible delay in payments," Computers \& Operations Research, vol. 35, no. 11, pp. 3562-3580, 2008.

[3] H. Soni and N. H. Shah, "Optimal ordering policy for stockdependent demand under progressive payment scheme," European Journal of Operational Research, vol. 184, no. 1, pp. 91-100, 2008.

[4] J.-T. Teng, I.-P. Krommyda, K. Skouri, and K.-R. Lou, "A comprehensive extension of optimal ordering policy for stockdependent demand under progressive payment scheme," European Journal of Operational Research, vol. 215, no. 1, pp. 97-104, 2011.

[5] B. Sarkar, "An EOQ model with delay in payments and time varying deterioration rate," Mathematical \& Computer Modelling, vol. 55, no. 3-4, pp. 367-377, 2012.

[6] J. T. Teng, J. Min, and Q. H. Pan, "Economic order quantity model with trade credit financing for non-decreasing demand," Omega, vol. 40, no. 3, pp. 328-335, 2012.

[7] S. K. Goyal, "Economic order quantity under conditions of permissible delay in payments," Journal of the Operational Research Society, vol. 36, no. 4, pp. 335-338, 1985.

[8] P. Chu, K.-J. Chung, and S.-P. Lan, "Economic order quantity of deteriorating items under permissible delay in payments," Computers \& Operations Research, vol. 25, no. 10, pp. 817-824, 1998.

[9] S. P. Aggarwal and C. K. Jaggi, "Ordering policies of deteriorating items under permissible delay in payments," Journal of the Operational Research Society, vol. 46, no. 5, pp. 658-662, 1995.

[10] A. M. M. Jamal, B. R. Sarker, and S. Wang, "An ordering policy for deteriorating items with allowable shortage and permissible delay in payment," Journal of the Operational Research Society, vol. 48, no. 8, pp. 826-833, 1997.

[11] H.-J. Chang and C.-Y. Dye, "An inventory model for deteriorating items with partial backlogging and permissible delay in payments," International Journal of Systems Science, vol. 32, no. 3, pp. 345-352, 2001.

[12] J.-T. Teng, "On the economic order quantity under conditions of permissible delay in payments," Journal of the Operational Research Society, vol. 53, no. 8, pp. 915-918, 2002.

[13] K.-J. Chung and Y.-F. Huang, "The optimal cycle time for EPQ inventory model under permissible delay in payments," International Journal of Production Economics, vol. 84, no. 3, pp. 307-318, 2003.

[14] R. Uthayakumar and P. Parvathi, "A two-stage supply chain with order cost reduction and credit period incentives for deteriorating items," International Journal of Advanced Manufacturing Technology, vol. 56, no. 5-8, pp. 799-807, 2011. 
[15] Y.-F. Huang, "Optimal retailer's ordering policies in the EOQ model under trade credit financing," Journal of the Operational Research Society, vol. 54, no. 9, pp. 1011-1015, 2003.

[16] Q. Hao, L. Liang, Y. Yu-gang, and D. Shao-fu, "EOQ model under three Levels of order-size-dependent delay in payments," Journal of Systems \& Management, vol. 16, pp. 669-672, 2007.

[17] Y.-F. Huang, "Optimal retailer's replenishment decisions in the EPQ model under two levels of trade credit policy," European Journal of Operational Research, vol. 176, no. 3, pp. 1577-1591, 2007.

[18] J.-T. Teng and C.-T. Chang, “Optimal manufacturer's replenishment policies in the EPQ model under two levels of trade credit policy," European Journal of Operational Research, vol. 195, no. 2, pp. 358-363, 2009.

[19] R. Du, A. Banerjee, and S.-L. Kim, "Coordination of twoechelon supply chains using wholesale price discount and credit option," International Journal of Production Economics, vol. 143, no. 2, pp. 327-334, 2013.

[20] J. Wu, L.-Y. Ouyang, L. E. Cárdenas-Barrón, and S. K. Goyal, "Optimal credit period and lot size for deteriorating items with expiration dates under two-level trade credit financing," European Journal of Operational Research, vol. 237, no. 3, pp. 898-908, 2014.

[21] H. Hwang and S. W. Shinn, "Retailer's pricing and lot sizing policy for exponentially deteriorating products under the condition of permissible delay in payments," Computers \& Operations Research, vol. 24, no. 6, pp. 539-547, 1997.

[22] S. Panda, S. Senapati, and M. Basu, "Optimal replenishment policy for perishable seasonal products in a season with ramp-type time dependent demand," Computers \& Industrial Engineering, vol. 54, no. 2, pp. 301-314, 2008.

[23] K. Skouri, I. Konstantaras, S. Papachristos, and I. Ganas, "Inventory models with ramp type demand rate, partial backlogging and Weibull deterioration rate," European Journal of Operational Research, vol. 192, no. 1, pp. 79-92, 2009.

[24] S. K. Manna and K. S. Chaudhuri, "An EOQ model with ramp type demand rate, time dependent deterioration rate, unit production cost and shortages," European Journal of Operational Research, vol. 171, no. 2, pp. 557-566, 2006.

[25] B. Mandal, "An EOQ inventory model for Weibull distributed deteriorating items under ramp type demand and shortages," Opsearch, vol. 47, no. 2, pp. 158-165, 2010.

[26] S. R. Singh and C. Singh, "Supply chain model with stochastic lead time under imprecise partially backlogging and fuzzy ramp-type demand for expiring items," International Journal of Operational Research, vol. 8, no. 4, pp. 511-522, 2010.

[27] V. K. Mishra and L. S. Singh, "Inventory model for ramp type demand, time dependent deteriorating items with salvage value and shortages," International Journal of Applied Mathematics \& Statistics, vol. 23, no. 11, pp. 84-91, 2011.

[28] S. Agrawal and S. Banerjee, "Two-warehouse inventory model with ramp-type demand and partially backlogged shortages," International Journal of Systems Science, vol. 42, no. 7, pp. 11151126, 2011.

[29] T. Roy and K. Chaudhuri, "A finite time horizon EOQ model with ramp-type demand rate under inflation and timediscounting," International Journal of Operational Research, vol. 11, no. 1, pp. 100-118, 2011.

[30] S. Agrawal, S. Banerjee, and S. Papachristos, "Inventory model with deteriorating items, ramp-type demand and partially backlogged shortages for a two warehouse system," Applied Mathematical Modelling, vol. 37, no. 20-21, pp. 8912-8929, 2013.
[31] M. A. Ahmed, T. A. Al-Khamis, and L. Benkherouf, "Inventory models with ramp type demand rate, partial backlogging and general deterioration rate," Applied Mathematics \& Computation, vol. 219, no. 9, pp. 4288-4307, 2013.

[32] S. Saha, "Optimal order quantity of retailer with quadratic ramp type demand under supplier trade credit financing," International Journal of Management Science \& Engineering Management, vol. 9, no. 2, pp. 103-188, 2014.

[33] S. S. Mishra and P. K. Singh, "Computational approach to an inventory model with ramp-type demand and linear deterioration," International Journal of Operational Research, vol. 15, no. 3, pp. 337-357, 2012.

[34] Y.-C. Huang, K.-H. Wang, and C.-T. Tung, "Optimal order policy for single period products under payment delay with ramp type demand rate," Journal of Information \& Optimization Sciences, vol. 31, no. 6, pp. 1337-1360, 2010.

[35] G. Darzanou and K. Skouri, "An inventory system for deteriorating products with ramp-type demand rate under two-level trade credit financing," Advances in Decision Sciences, vol. 2011, Article ID 761961, 15 pages, 2011.

[36] S. K. Manna and C. Chiang, "Economic production quantity models for deteriorating items with ramp type demand," International Journal of Operational Research, vol. 7, no. 4, pp. 429444, 2010.

[37] K. Skouri, I. Konstantaras, S. K. Manna, and K. S. Chaudhuri, "Inventory models with ramp type demand rate, time dependent deterioration rate, unit production cost and shortages," Annals of Operations Research, vol. 191, no. 1, pp. 73-95, 2011.

[38] H. N. Soni and K. A. Patel, "Optimal strategy for an integrated inventory system involving variable production and defective items under retailer partial trade credit policy," Decision Support Systems, vol. 54, no. 1, pp. 235-247, 2012. 


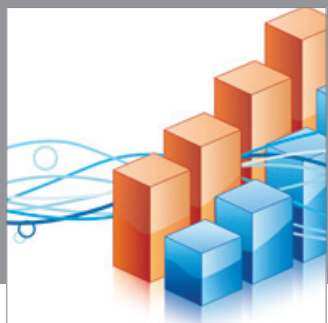

Advances in

Operations Research

mansans

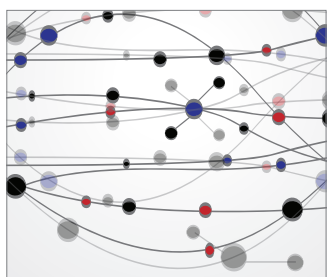

The Scientific World Journal
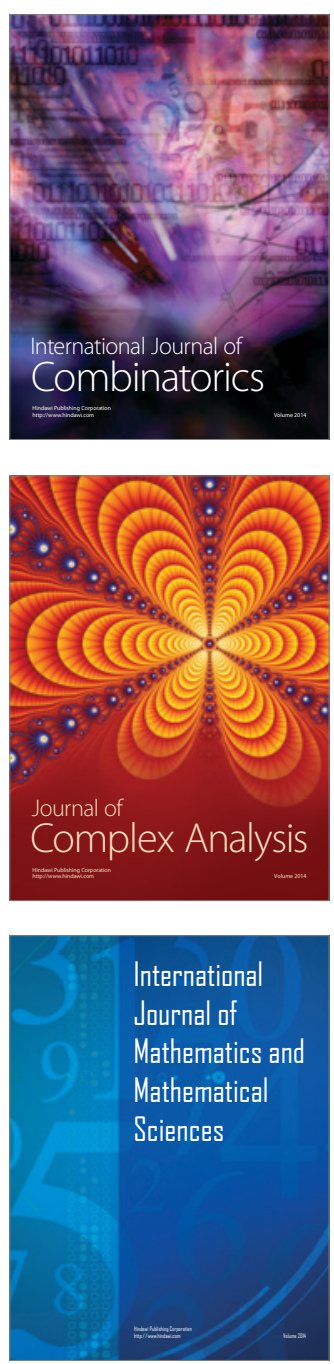
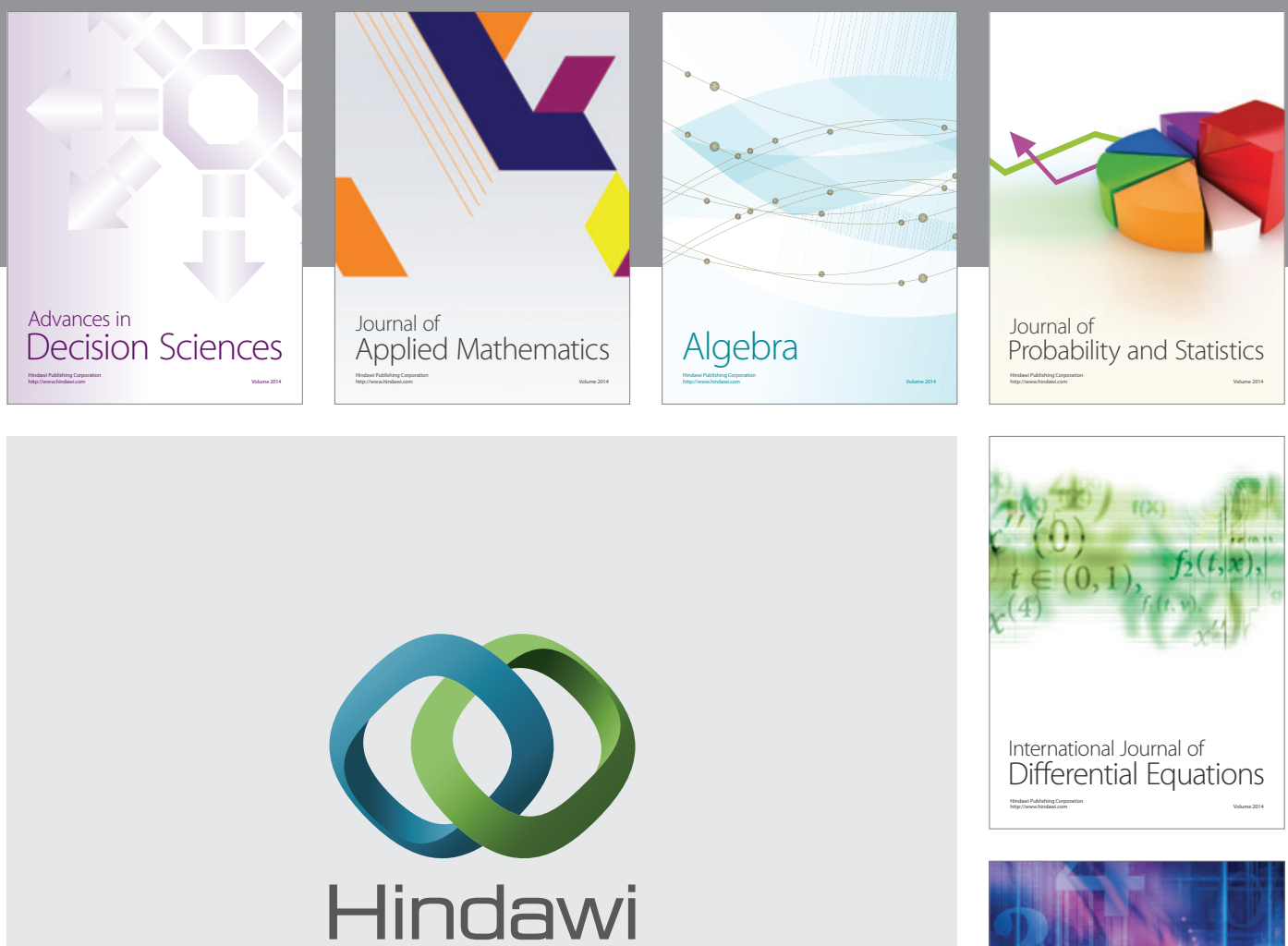

Submit your manuscripts at http://www.hindawi.com
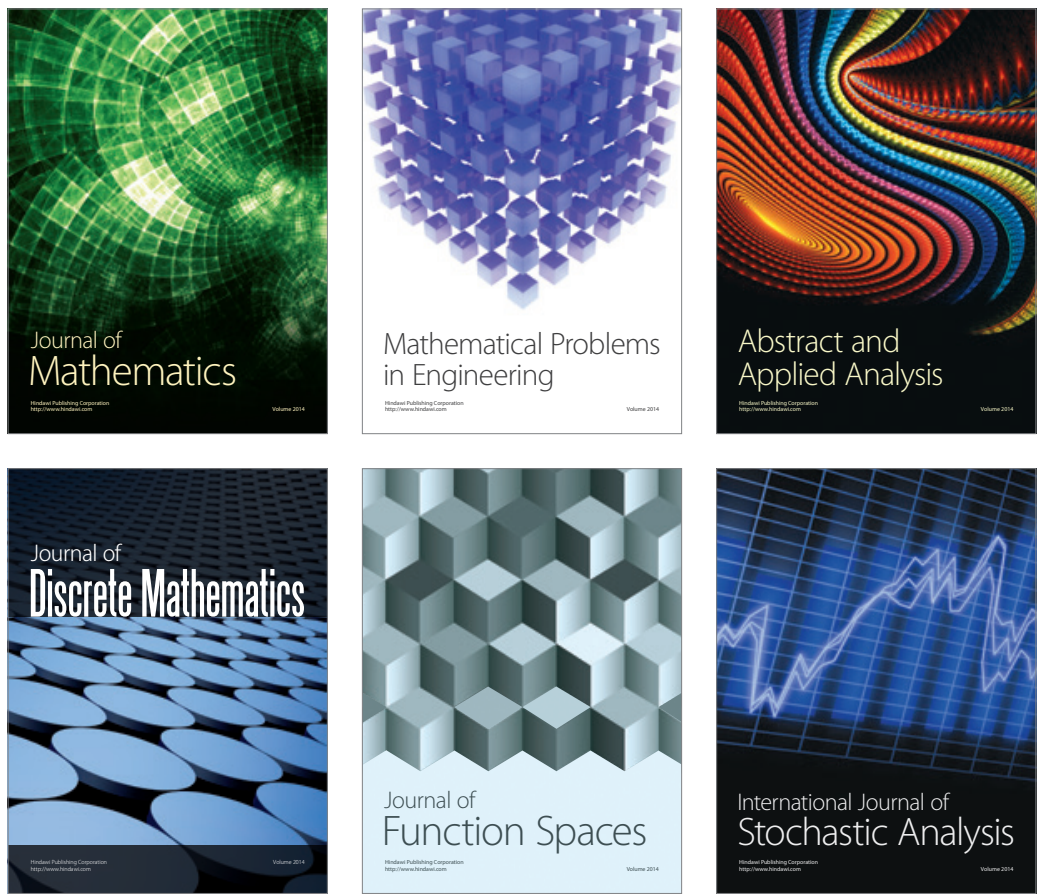

Journal of

Function Spaces

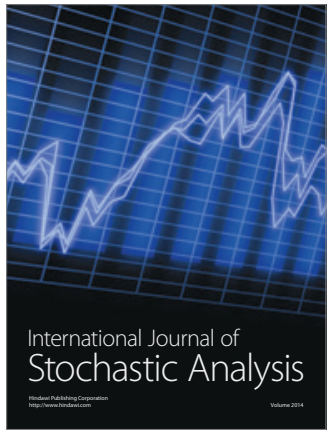

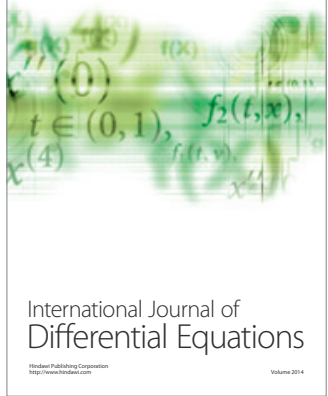
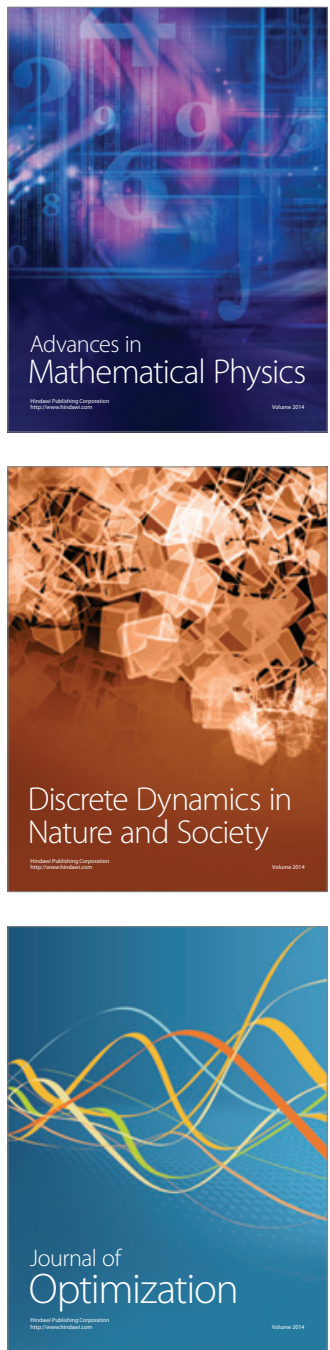